\title{
Protein kinase C-gamma knockout mice show impaired hippocampal short-term memory while preserved long-term memory
}

Maria Gomis-González*1,\$, Lorena Galera-López*1, Marc Ten-Blanco ${ }^{1, \&}$, Arnau Busquets-

*equal contribution

${ }^{1}$ Laboratory of Neuropharmacology. Department of Experimental and Health Sciences.

University Pompeu Fabra, 08003 Barcelona, Spain.

${ }^{2}$ IMIM (Hospital del Mar Medical Research Institute), Barcelona, Spain.

Present address:

\$ Integrative Pharmacology and Systems Neuroscience Research Group, Hospital del Mar Medical Research Institute, 08003 Barcelona, Spain.

${ }^{\&}$ School of Experimental Sciences, Universidad Francisco de Vitoria, UFV, 28223, Pozuelo de Alarcón, Madrid, Spain

${ }^{\#}$ Faculty of Health and Medical Sciences, University of Surrey, Guildford, United Kingdom

†Corresponding authors:

Andrés Ozaita, Laboratori de Neurofarmacologia, Facultat de Ciències de la Salut i de la Vida, Universitat Pompeu Fabra, Parc de Recerca Biomèdica de Barcelona, C/ Doctor Aiguader 88, 08003 Barcelona, Spain. Phone: +34-93-3160823; Fax: + 34-93-3160901; e-mail: andres.ozaita@upf.edu

$\dagger$ Rafael Maldonado, Laboratori de Neurofarmacologia, Facultat de Ciències de la Salut i de la Vida, Universitat Pompeu Fabra, Parc de Recerca Biomèdica de Barcelona, C/ Doctor Aiguader 88, 08003 Barcelona, Spain. Phone: +34-93-3160824; Fax: + 34-93-3160901; e-mail: rafael.maldonado@upf.edu 
Abstract

The brain encodes, stores, and retrieves relevant information in the form of memories that are

4 classified as short-term (STM) and long-term memories (LTM) depending on the interval between acquisition and retrieval. It is classically accepted that STM undergo a consolidation process to form LTM, but the molecular determinants involved are not well understood. Among the molecular components relevant for memory formation, we focused our attention on the protein kinase $\mathrm{C}$ (PKC) family of enzymes since they control key aspects of the synaptic plasticity and memory. Within the different PKC isoforms, PKC-gamma has been specifically associated with learning and memory since mice lacking this isoform (PKC-gamma $\mathrm{KO}$ mice)

11 showed mild cognitive impairment and deficits in hippocampal synaptic plasticity. We now reveal that PKC-gamma $\mathrm{KO}$ mice present a severe impairment in hippocampal-dependent STM using different memory tests including the novel object-recognition and novel place-recognition,

14 context fear conditioning and trace fear conditioning. In contrast, no differences between genotypes were observed in an amygdala-dependent test, the delay fear conditioning. Strikingly, all LTM tasks that could be assessed $24 \mathrm{~h}$ after acquisition were not perturbed in the KO mice. The analysis of c-Fos expression in several brain areas after trace fear conditioning acquisition showed a blunted response in the dentate gyrus of PKC-gamma KO mice compared to WT mice, but such differences between genotypes were absent when the amygdala or the prefrontal cortex were examined. In the hippocampus, PKC-gamma was found to translocate to the membrane

21 after auditory trace, but not after delay fear conditioning. Together, these results indicate that PKC-gamma dysfunction affects specifically hippocampal-dependent STM performance and disclose PKC-gamma as a molecular player differentially involved in STM and LTM processes.

Keywords: short-term memory, long-term memory, PKC-gamma, memory acquisition, c-Fos expression 


\section{Introduction}

2 Memory is a brain function crucial for adaptive behavior characterized by the encoding, storage,

3 and retrieval of relevant information [1]. Memories can be classified according to their

4 permanence as short- and long-term memory (STM and LTM, respectively) [2]. STM encoding occurs rapidly in the hippocampus, while the consolidation process to form LTM involves other

6 brain areas including the neocortex [3-5].

7 The cellular and molecular mechanisms underlying STM consolidation into LTM are largely unknown, although specific players have been proposed $[1,6]$. Among those, the protein kinase $\mathrm{C}$ (PKC) family of enzymes, composed of serine/threonine protein kinases with a highly conserved catalytic domain, plays a relevant role in learning and memory [7-9]. This family

11 includes at least 12 isoforms involved in multiple physiological functions beyond learning and memory, such as cell growth and proliferation, differentiation, immune responses, apoptosis and angiogenesis, among others $[10,11]$, but their isoform specialization, if any, has not been yet clarified. PKC isoforms are classified in three groups based on their structure and activation mechanism $[8,10]:$ i) the conventional/classical isoforms (alpha, beta-I, beta-II and gamma) are activated by both calcium and diacylglycerol (DAG), ii) the novel isoforms (delta, epsilon, eta, theta and mu) are activated by DAG in a calcium-independent manner, and iii) the atypical isoforms (zeta and lambda) do not require neither calcium nor DAG to be activated, but they are sensitive to phospholipids $[11,12]$.

The PKC-gamma isoform is highly expressed in the hippocampus, the cortex and the amygdala $[13,14]$, primarily in the dendrites and neuronal cell bodies $[15,16]$. At the cellular level, PKCgamma was described to translocate to the cell membrane after a single learning episode in the context fear conditioning [17]. PKC-gamma phosphorylates, among other preferential substrates, the N-methyl-D-aspartate receptor (NMDAR) subunit NR1, the functionally essential subunits in NMDAR tetramers [18]. Phosphorylation of NR1 plays a key role in synaptic plasticity, memory and learning $[19,20]$. Interestingly, the genetic deletion of the Prkcg gene encoding 
1 PKC-gamma in mice revealed a mild alteration in spatial memory using the Morris water maze

2 task, and in repetitive-pairing context-dependent fear conditioning when LTM was assessed [21],

3 while STM performance was not explored. In addition, hippocampal long-term potentiation

4 (LTP) was found affected in PKC-gamma knockout (KO) mice, while other forms of synaptic

5 plasticity, such as long-term depression and paired-pulse facilitation were similar to wild-type

6 (WT) controls [15], overall suggesting that PKC-gamma may be a regulatory component of LTP.

7 The objective of this work was to further investigate the relevance of PKC-gamma deletion in

8 cognitive performance and on the associated cellular responses during memory acquisition. 


\section{$1 \quad$ Material and methods}

2 Animals

3 Male C57BL/6J wild-type mice (WT) and male constitutive PKC-gamma KO mice, B6;129P-

4 Pkctm1St1 [15] backcrossed to C57BL/6J for at least 10 generations were used at 8-16 weeks

5 of age (approx. 25-30 g). Animals were housed at controlled environmental conditions $\left(21 \pm 1^{\circ} \mathrm{C}\right.$

6 temperature and 55 $510 \%$ humidity). Food and water were available ad libitum. Lighting was

7 maintained at $12 \mathrm{~h}$ cycles (on at 8 am and off at $8 \mathrm{pm}$ ). All the experiments were performed during the light phase of the dark/light cycle. Animals were habituated to the experimental room and handled for one week before starting the experiments. All animal procedures were conducted in accordance with the standard ethical guidelines (European Communities Directive

11 2010/63/EU) and approved by the local ethical committee (Comitè Ètic d'Experimentació 12 Animal, CEEA-PRBB). All behavioral analyses were performed blind to the experimental 13 conditions.

Spontaneous alternation task

16 T-maze spontaneous alternation: Spatial working memory was assayed in a T-shaped maze 17 composed by two opposed arms and a perpendicular arm (T-shaped; $6 \mathrm{~cm}$ width $\mathrm{x} 30 \mathrm{~cm}$ length $18 \times 15 \mathrm{~cm}$ height). Animals were allowed to freely explore the maze for $9 \mathrm{~min}$, starting from the end of the same arm in the maze facing the wall. Entries into all arms of the maze were counted (traversing the head and two front paws was considered a valid entry) and the percentage of 21 spontaneous alternation was calculated taking into account the sequential entries in all three arms divided by the total number of possible alternations (total number of entries -2 ).

$23 \quad$ Y-maze spontaneous alternation: Additionally, spatial working memory was assayed in a second cohort of PKC-gamma KO and WT mice using a Y-shaped maze. This maze is composed by three identical arms that intersected at $120^{\circ}$ (Y-shaped; $6.5 \mathrm{~cm}$ width x $30 \mathrm{~cm}$ length $\mathrm{x} 15 \mathrm{~cm}$ height). Animal behavior was analyzed as described for the T-maze task. 


\section{1}

2

\section{Barnes maze}

Spatial learning and reference memory were assessed using the Barnes maze, as previously described [22]. The maze consists of a circular platform (90 $\mathrm{cm}$ in diameter) with 20 equally spaced holes through which mice may escape from a bright light (300 lx). Only one hole allows the escape to a dark/target box. Visual cues were placed surrounding the maze for navigational reference (Supp. Fig. 1). Smart v3.0 software was used to control the video-tracking system. Briefly, mice were first habituated to the maze. In this phase, animals were placed in the center of the maze covered by an opaque cylinder for $10 \mathrm{sec}$. After removal of the opaque cylinder, mice were gently guided to the target hole by surrounding them within a cylinder with transparent walls so mice could see where the scape hole was located. Then, they were left inside the target box for $2 \mathrm{~min}$ and then taken to the homecage. $1 \mathrm{~h}$ later, the first training phase was carried out. During training, each mouse performed 2 trials per day on 4 consecutive days. Each training trial started with the mouse placed in the center of the Barnes maze covered by an opaque cylinder for $10 \mathrm{sec}$. Then, animals were allowed to explore the maze for $3 \mathrm{~min}$. During this period, the number of primary errors to find the target hole were measured. Each training trial ended when the mouse entered the target box or after 3 min of exploration. The mouse was allowed to stay in the target box for $1 \mathrm{~min}$. When mice did not reach the target box within $3 \mathrm{~min}$, the experimenter guided the mouse gently to the escape box using a transparent cylinder. On day 5, the first test trial was conducted $24 \mathrm{~h}$ after the last training day. During the test trial, the target hole was closed. Animals were placed in the center of the maze covered by an opaque cylinder for $10 \mathrm{sec}$. Next, exploration was analyzed during $90 \mathrm{sec}$ to reveal the number of pokes in each hole. Using the tracking system, the time spent in each quadrant (target, opposite, left and right quadrants) and the distance travelled were measured. A second test trial was conducted to assess remote memory on day 12,7 days after the last training session. 
Novel object-recognition (NOR) test

Object-recognition memory was assayed in a V-shaped maze $(30 \mathrm{~cm}$ long x $4.5 \mathrm{~cm}$ wide x 15 $\mathrm{cm}$ height each corridor), as previously described $[23,24]$. On day 1 , mice were habituated to the empty maze for $9 \mathrm{~min}$. On day 2, mice were introduced in the maze for $9 \mathrm{~min}$, where 2 identical objects were presented, one at the end of each corridor. Memory was then tested at different times after acquisition to assess STM (10 min and $3 \mathrm{~h}$ ) or LTM (6 h, $24 \mathrm{~h}$ or $48 \mathrm{~h}$ ) (see diagram in Supp. Fig. 2a). For the memory test, mice were placed again in the $\mathrm{V}$-maze for a period of $9 \mathrm{~min}$, where a novel object replaced one of the familiar objects. The total time spent exploring each of the 2 objects (novel and familiar) was recorded, defining exploration as the orientation of the nose towards the object. A discrimination index (DI) was calculated as the difference between the time spent exploring either the novel (Tn) or familiar (Tf) object divided by the total time exploring both objects $(\mathrm{Tn}+\mathrm{Tf})(\mathrm{DI}=(\mathrm{Tn}-\mathrm{Tf}) /(\mathrm{Tn}+\mathrm{Tf}))$. A positive discrimination index reflects memory retention for the familiar object as mice explore the novel object for longer than the familiar object. Mice exploring less than $10 \mathrm{sec}$ both objects, or less than $3 \mathrm{sec}$ one of the objects on the memory test were excluded from the analysis.

\section{Novel place-recognition (NPR) test}

Mice were first habituated to an empty open field $(25 \mathrm{~cm}$ long x $25 \mathrm{~cm}$ wide x $15 \mathrm{~cm}$ height) for 10 min during 2 consecutive days. On day 3, mice were trained for 10 min with 2 identical objects (training phase) located at 2 opposite corners of the open field. The test phase was performed 3 h (STM assay) or $24 \mathrm{~h}$ (LTM assay) after the last habituation session, where one of the objects was located in a different corner (novel location) (see diagram in Supp. Fig. 2b). The time spent exploring both objects in the novel and familiar locations were computed to calculate the discrimination index similarly to the NOR test. Total exploration time during the test was considered as a measure of general activity. Mice that explored objects for less than $5 \mathrm{sec}$ were excluded from the analysis. 


\section{Consecutive NOR/NPR and NPR/NOR}

In order to assess STM and LTM in the same mouse, we combined NOR and NPR tests at $3 \mathrm{~h}$ and $24 \mathrm{~h}$, both of them performed in an empty open field $(25 \mathrm{~cm}$ long x $25 \mathrm{~cm}$ wide $\mathrm{x} 15 \mathrm{~cm}$ height). First, we used a set of animals that performed 2 training sessions with the same objects located at the same place. Then, mice were evaluated for STM in the NOR test ( $3 \mathrm{~h}$ after the last training session) and for LTM in the NPR test ( $24 \mathrm{~h}$ after the last training session). In addition, another set of mice were evaluated first for STM in the NPR test and for LTM in the NOR test after the training sessions (see diagram in Supp. Fig. 3).

\section{Fear conditioning}

Context fear conditioning: Context recognition memory was assayed in a conditioning chamber with an electrifiable floor, as previously described [23]. On day 1, mice were placed in the shuttle box and after a period of free exploration, mice received a footshock (Unconditioned stimulus (US): $2 \mathrm{sec}, 0.6 \mathrm{~mA}$ intensity). Freezing behavior (lack of movement except for respiration) due to context re-exposure was assessed in the same conditioning chamber $1 \mathrm{~h}, 3 \mathrm{~h}$ or $24 \mathrm{~h}$ after the conditioning session. For testing, mice were placed again in the conditioning chamber for 5 min in absence of the shock and the freezing behavior was recorded (see diagram in Supp. Fig. 2c). Cued fear conditioning: On day 1 , mice were placed in a conditioning chamber with an electrifiable floor and after 2 min of free exploration, they were exposed to an auditory stimulus (conditioned stimulus, CS) for $1 \mathrm{~min}$. Just at the end of the auditory stimulus (delay fear conditioning) or $15 \mathrm{sec}$ after the end of the auditory stimulus (trace fear conditioning), the animal received a footshock (US: $2 \mathrm{sec}, 0.35 \mathrm{~mA}$ intensity). Different groups of mice were tested $3 \mathrm{~h}$ (for STM) or $24 \mathrm{~h}$ (for LTM) later by placing them in a new environment (glass cylinder for observation in a new experimental room) with the presence of the CS. Freezing behavior due to CS re-exposure was recorded for $1 \mathrm{~min}$ (see diagram in Supp. Fig. 2d).

\section{Locomotor activity test}


1 Spontaneous locomotor responses of PKC-gamma $\mathrm{KO}$ and $\mathrm{WT}$ mice were evaluated in

2 individual locomotor activity boxes $(10.8 \mathrm{~cm}$ width $\times 20.3 \mathrm{~cm}$ length $\times 18.6 \mathrm{~cm}$ high), (Imetronic,

3 Pessac, France) under dim light (20-25 1x). The total activity (number of beam breaks) and the

4 total number of rearings was detected during $10 \mathrm{~min}$ by infrared sensors.

\section{Plantar test}

7 Heat hyperalgesia was evaluated by measuring paw withdrawal latency in response to radiant heat with a plantar test apparatus (Ugo Basile, Italy). Mice were placed in Plexiglas boxes $(9 \mathrm{~cm}$ diameter, $20 \mathrm{~cm}$ height) positioned on a glass surface and habituated to the environment for 30 min before testing. The mean paw withdrawal latencies for left and right hind paws were

11 determined from the average of 3 separate trials, taken at 5-10 min intervals to prevent thermal 12 sensitization. A cut-off time of $20 \mathrm{sec}$ was used to prevent tissue damage.

\section{Brain samples for immunoblot analysis}

Brain samples were obtained from PKC-gamma KO and WT mice in basal conditions or 30 min after being exposed to the trace or the delay fear conditioning protocol. Hippocampal tissues were dissected from brains, frozen on dry ice and stored at $-80{ }^{\circ} \mathrm{C}$ until used, as previously reported [23]. Samples from all animal groups, in each experiment, were processed in parallel, to minimize inter-assay variations.

\section{Sample preparation of total solubilized fraction}

From total solubilized fraction brain areas were processed as described previously [25]. Frozen

23 brain areas were dounce homogenized in 30 volumes of lysis buffer $(50 \mathrm{mmol} / \mathrm{L}$ Tris $\mathrm{HCl} \mathrm{pH}$

$247.4,150 \mathrm{mmol} / \mathrm{L} \mathrm{NaCl}, 10 \%$ glycerol, $1 \mathrm{mmol} / \mathrm{L}$ EDTA, $10 \mu \mathrm{g} / \mathrm{mL}$ aprotinin, $1 \mu \mathrm{g} / \mathrm{mL}$ leupeptine,

$251 \mu \mathrm{g} / \mathrm{mL}$ pepstatin, $1 \mathrm{mmol} / \mathrm{L}$ phenylmethylsulfonyl fluoride, $1 \mathrm{mmol} / \mathrm{L}$ sodium orthovanadate, $26100 \mathrm{mmol} / \mathrm{L}$ sodium fluoride, $5 \mathrm{mmol} / \mathrm{L}$ sodium pyrophosphate, and $40 \mathrm{mmol} / \mathrm{L}$ beta- 
1 glycerolphosphate) plus $1 \%$ Triton $\mathrm{X}-100$. After $10 \mathrm{~min}$ incubation at $4{ }^{\circ} \mathrm{C}$, samples were

2 centrifuged at $16,000 \mathrm{~g}$ for $20 \mathrm{~min}$ to remove insoluble debris. Protein contents in the

3 supernatants were determined by DC-micro plate assay (Bio-Rad, Madrid, Spain), following

4 manufacturer's instructions.

Preparation of membrane and cytosolic fractions

7 Frozen brain areas were dounze-homogenized in 30 volumes of cytosol buffer $(50 \mathrm{mmol} / \mathrm{L}$ Tris$\mathrm{HCl} \mathrm{pH}$ 7.4, $0.32 \mathrm{~mol} / \mathrm{L}$ saccharose, $1 \mathrm{mmol} / \mathrm{L}$ EDTA, $10 \mu \mathrm{g} / \mathrm{mL}$ aprotinin, $1 \mu \mathrm{g} / \mathrm{mL}$ leupeptine, $1 \mu \mathrm{g} / \mathrm{mL}$ pepstatin, $1 \mathrm{mmol} / \mathrm{L}$ phenylmethylsulfonyl fluoride, $1 \mathrm{mmol} / \mathrm{L}$ sodium orthovanadate, $100 \mathrm{mmol} / \mathrm{L}$ sodium fluoride, $5 \mathrm{mmol} / \mathrm{L}$ sodium pyrophosphate, and $40 \mathrm{mmol} / \mathrm{L}$ beta11 glycerolphosphate) and immediately centrifuged at low speed $(1,000 \mathrm{~g})$ for $10 \mathrm{~min}$ at $4^{\circ} \mathrm{C}$. The supernatant (S1) was recovered. The pellet was resuspended with $600 \mathrm{ul}$ of cytosol buffer and immediately centrifuged at low speed $(1,000 \mathrm{~g})$ for $10 \mathrm{~min}$ at $4^{\circ} \mathrm{C}$. The supernatant (S2) was recovered. Both supernatant $(\mathrm{S} 1+\mathrm{S} 2)$ were centrifuged at $16,000 \mathrm{~g}$ for $30 \mathrm{~min}$ at $4^{\circ} \mathrm{C}$. The supernatant was recovered and used as cytosolic fraction. The pellet was resuspended in 5 volumes of membrane buffer $(50 \mathrm{mmol} / \mathrm{L}$ Tris-HCl pH 7.4, $1 \mathrm{mmol} / \mathrm{L}$ EDTA, $150 \mathrm{mmol} / \mathrm{L} \mathrm{NaCl}$, $10 \%$ glycerol, $10 \mu \mathrm{g} / \mathrm{mL}$ aprotinin, $1 \mu \mathrm{g} / \mathrm{mL}$ leupeptine, $1 \mu \mathrm{g} / \mathrm{mL}$ pepstatin, $1 \mu \mathrm{mmol} / \mathrm{L}$ phenylmethylsulfonyl fluoride, $1 \mathrm{mmol} / \mathrm{L}$ sodium orthovanadate, $100 \mathrm{mmol} / \mathrm{L}$ sodium fluoride, $5 \mathrm{mmol} / \mathrm{L}$ sodium pyrophosphate, and $40 \mathrm{mmol} / \mathrm{L}$ beta-glycerolphosphate) and used as membrane fraction. Protein content in both the cytosolic and the membrane fraction were determined by DC-micro plate assay (Bio-Rad), following manufacturer's instructions.

Immunoblot analysis

24 Hippocampal protein samples were prepared as described previously [25]. The antibodies used for immunoblot were: PKC-alpha (1:500), PKC-beta I (1:500), PKC-beta II (1:500), PKC-delta 
1 Biotechnology, Santa Cruz, CA, USA), PKC-gamma (1:500) (Abcam, UK), pNR1 (Ser890)

2 (1:200) (Cell Signaling Technologies, The Netherlands) and NR1 (1:500) (Novus Biologicals,

3 Spain). Primary antibodies were detected with horseradish peroxidase-conjugated anti-rabbit

$4 \quad(1: 15,000)$ or anti-mouse $(1: 15,000)$ antibodies (Cell Signaling Technologies) and visualized by

5 enhanced chemiluminiescence detection (Luminata Forte Western HRP substrate,

6 MerckMillipore). Digital images were acquired on ChemiDoc XRS System (Bio-Rad) and

7 quantified by The Quantity One software v4.6.3 (Bio-Rad). Optical density values for target proteins were normalized to GAPDH $(1: 15,000)$ (Santa Cruz Biotechnology) or NR1 as loading control in the same sample and expressed as a percentage of the control group (WT).

Tissue preparation for immunofluorescence

Mice were perfused 120 min after being exposed to a training session of the trace or the delay fear conditioning. Mice from the control group were perfused 120 minutes after going through the same protocol (handling, and exposure to the fear conditioning box and auditory stimulus) but without receiving the footshock. Mice were deeply anesthetized by intraperitoneal injection $(0.2 \mathrm{ml} / 10 \mathrm{~g}$ of body weight $)$ of a mixture of ketamine $(100 \mathrm{mg} / \mathrm{kg})$ and xylazine $(20 \mathrm{mg} / \mathrm{kg})$ prior to intracardiac perfusion with $4 \%$ paraformaldehyde in $0.1 \mathrm{M} \mathrm{Na}_{2} \mathrm{HPO}_{4} / 0.1 \mathrm{M} \mathrm{NaH}_{2} \mathrm{PO}_{4}$ buffer (PB), pH 7.5, delivered with a peristaltic pump at $19 \mathrm{ml} / \mathrm{min}$ flow for $3 \mathrm{~min}$. Subsequently, brains were extracted and post-fixed in the same fixative solution for $24 \mathrm{~h}$ and transferred to a solution of $30 \%$ sucrose in PB overnight at $4{ }^{\circ} \mathrm{C}$. Coronal frozen sections $(30 \mu \mathrm{m})$ of the dorsal hippocampus (coordinates relative to Bregma: $-1.22 \mathrm{~mm}$ to $-1.82 \mathrm{~mm}$ ), basolateral amygdala (from Bregma: $-1.22 \mathrm{~mm}$ to $-1.82 \mathrm{~mm}$ ) and the prelimbic prefrontal cortex (from Bregma: 1.98 $\mathrm{mm}$ to $1.54 \mathrm{~mm}$ ) were obtained on a freezing microtome and stored in a solution of $5 \%$ sucrose at $4{ }^{\circ} \mathrm{C}$ until used.

\section{Immunofluorescence}


1 Free-floating brain slices were rinsed in PB, blocked in a solution containing 3\% donkey serum

(DS) (Sigma-Aldrich, Madrid, Spain) and 0.3\% Triton X-100 (T) in PB (DS-T-PB) at room temperature for $2 \mathrm{~h}$, and incubated overnight in the same solution with the primary antibody to c-Fos (sc-7202, 1:1000, rabbit, Santa Cruz Biotechnology), PKC-gamma (1:1000, rabbit, Abcam, UK) and neuronal nuclei (NeuN) (1:1000, mouse, MerckMillipore), at $4{ }^{\circ} \mathrm{C}$. The next day, after 3 rinses in $\mathrm{PB}$, sections were incubated at room temperature with the secondary antibody AlexaFluor-555 donkey anti-rabbit (c-Fos and PKC-gamma) (1:500, Life Technologies, Thermo Fisher Scientific, MA, USA) and secondary antibody AlexaFluor-488 goat anti-mouse (NeuN) (1:1000, Jackson ImmunoResearch, UK) in DS-T-PB for 2 h. After incubation, sections were rinsed and mounted immediately after onto glass slides coated with gelatin in Fluoromont-G with 4',6-diamidino-2-phenylindole (DAPI) (Invitrogen, Thermo Fisher Scientific, MA, USA) as counterstaining.

\section{Image analysis.}

Immunostained brain sections were analyzed with a 10x objective using a Leica DMR microscope (Leica Microsystems, Wetzlar, Germany) equipped with a digital camera Leica DFC 300FX (Leica Microsystems). For prelimbic cortex analysis, a $430 \mu \mathrm{m}$ sided square region of interest (ROI) was delimited for quantification. For basolateral amygdala and dentate gyrus analysis the DAPI signal was used for the delimitation of this area in each image for quantification. The images were processed using the ImageJ analysis software. c-Fos positive neurons in each brain area were quantified using the automatic 'particle counting' option with a fixed configuration that solely detected c-Fos positive cell bodies matching common criteria of size and circularity. A fixed threshold interval was set to distinguish the c-Fos positive neurons from the background. In addition, all quantifications were individually checked by an expert observer blind to the experimental conditions. Six representative brain sections of each mouse were quantified, and the average number of c-Fos-positive neurons was calculated for each 
1 mouse. The data are expressed as the mean number of c-Fos-positive cells per squared $\mathrm{mm}(\mathrm{n}=$

2 4-6 mice per experimental group). For the c-Fos data the displayed images were flipped for

3 orientation consistency and transformed to grey scale for display. Images for PKC-gamma

4 detection were adjusted for brightness and contrast for display.

$6 \quad$ Statistical analysis

7 Comparisons between groups were performed by one-way or two-way analysis of variance 8 (ANOVA) for multiple-group comparisons, depending on the factors involved. Post hoc 9 comparisons were performed by Bonferroni test only when significant main effect of one-way 10 ANOVA or significant effect of factors or interaction between factors of two-way ANOVA were 11 revealed. The statistical analysis was performed using STATISTICA (StatSoft) software. The 12 artwork was designed using GraphPad Prism 7. All results were expressed as mean \pm s.e.m. 13 Differences were considered statistically significant when $p<0.05$. 


\section{Results}

2 Lack of PKC isoform compensation in hippocampal PKC-gamma KO samples

3 In order to discard any compensatory effect in the PKC-gamma KO mice, the expression of all

4 the PKC isoforms bearing a Ser residue at the hydrophobic domain, similar to PKC-gamma, was

5 studied in hippocampal homogenates. As expected, the immunodetection of PKC-gamma

6 confirmed the absence of this isoform in the hippocampus of PKC-gamma KO mice compared

7 to WT controls (Fig. 1a). Then, immunodetection of PKC-alpha, -beta I, -beta II, -epsilon, -eta,

8 -delta and -theta isoforms (Fig. 1b-h) revealed no significant differences between WT and PKC-

9 gamma KO mice. The immunofluorescence detection of PKC-gamma protein in WT mice was

10 clearly specific in all subregions of the hippocampus, including CA1 and dentate gyrus,

11 compared to the background levels detected in the PKC-gamma KO mice (Fig. 1i)

PKC-gamma KO mice show specific spatial memory deficits

14 PKC-gamma KO and WT mice were analyzed in the spontaneous alternation task to assess working memory. The T-maze task (Fig. 2a) revealed a significant decrease in the number of spontaneous alternations performed by the PKC-gamma KO mice compared to the WT control mice, pointing to a significant deficit in spatial working memory. This deficit was also observed with the Y-maze task (Fig. 2b). No differences in any of the tasks were observed between genotypes in the total number of corridor entries, discarding an effect on general exploration or locomotion as a confounding factor (Supp. Fig. 4a, b).

21 Spatial learning and long-term memory (LTM) were also studied using the Barnes maze (Fig. 2c,

d). Both genotypes showed similar spatial learning during the spatial training sessions (Supp. Fig. 5a). Then, recent (24 h after the last training) (Fig. 2c) and remote ( $7 \mathrm{~d}$ after the last training) (Fig. 2d) spatial LTM assessment showed a significant recall of the target quadrant in both genotypes, although PKC-gamma KO mice showed decreased accuracy compared to WT mice 
1 (Supp. Fig. 5b-e). No differences between genotypes were observed in the locomotor activity

2 during the Barnes test performance (Supp. Fig. 5f, g) discarding a motility bias in this test.

3

Short-term non-emotional memory performance is impaired in mice lacking PKC-gamma

5 Non-emotional memory performance was evaluated in PKC-gamma KO and WT mice using 2 memory tasks: the novel object-recognition (NOR) test (Fig. 3a) and the novel place-recognition (NPR) test (Fig. 3b). STM performance in these tasks (10 min and $3 \mathrm{~h}$ after training) was significantly impaired in PKC-gamma $\mathrm{KO}$ mice. However, no differences between genotypes were observed in the same tasks when memory was assessed beyond $6 \mathrm{~h}$ of the training session (Fig. 3a, b). Such specific differences were not related to exploratory behavior or motility since total exploration times were similar between genotypes in the memory tests (Supp. Fig. 6a-g), and locomotor activity assessment did not reveal genotype divergences in overall activity (Fig. 3c). To further discard differences between animal batches, both STM and LTM were tested in the same animal combining the two non-emotional memory tasks previously described. One set of animals performed consecutively the NOR test to study STM, and the NPR test to study LTM. Another set of animals performed the NPR test to study STM followed by the NOR test to study LTM. Such approach further demonstrated that PKC-gamma KO mice present significant nonemotional STM, but not LTM deficits, independent of the memory task performed in the first place (Supp. Fig. 7 a,b).

\section{PKC-gamma KO mice present deficits in hippocampal-dependent short-term fear memory.}

Fear memory was assessed using the context recognition test (Fig. 4a), the trace fear conditioning (Fig. 4b) and the delay fear conditioning (Fig. 4c) paradigms in PKC-gamma KO and WT mice. Memory performance was similar between both genotypes when LTM was studied in all three paradigms (Fig. 4a-c). In contrast, significant differences were observed in STM performance 
1 depending on the memory task assessed. While PKC-gamma KO mice displayed a significant

2 STM impairment in hippocampal-dependent tasks, such as the context recognition at $1 \mathrm{~h}$ and $3 \mathrm{~h}$

3 (Fig. 4a) and the trace fear conditioning (Fig. 4b), no deficits were observed in the delay fear

4 conditioning (Fig. 4c), an hippocampal-independent task [26]. A potential bias between genotypes in STM performance due to footshock sensitivity was disregarded based on the similar performance of both genotypes observed when LTM was assessed, and on the similar nociceptive sensitivity displayed by both genotypes in response to plantar stimulation (Fig. 4d).

PKC-gamma KO mice differentially express c-Fos in the dentate gyrus following the trace, but not the delay fear conditioning schedule

11 Cued fear conditioned memory encoding involves the expression of the immediate-early gene cFos in a subpopulation of hippocampal cells [27]. Thus, we hypothesized that PKC-gamma KO

13 and WT mice may differently encode hippocampal-dependent fear memories. For this reason, 14 independent cohorts of mice were exposed to trace or delay fear conditioning paradigms, using mice handled similarly but not exposed to the footshock as control group. Then, we analyzed the expression of c-Fos in memory relevant brain areas. Quantification of c-Fos positive cells in the dentate gyrus of the hippocampus, a sub-region where memory-associated cells have been allocated [28], revealed a sharp increase in c-Fos positive cells after trace fear conditioning training in WT mice, but not in PKC-gamma KO mice (Fig. 5a). Interestingly, c-Fos expression was comparable between genotypes after delay fear conditioning training (Fig. 5a), a non-

21 hippocampal-dependent task that had not shown differences between genotypes at STM (Fig. 4c). No differences between genotypes were found when other brain regions were studied for cFos expression including the basolateral amygdala (Fig. 5b) and the prelimbic cortex (Fig. 5c), pointing to a region-specific impairment in c-Fos expression in $\mathrm{PKC}$-gamma $\mathrm{KO}$ mice. Reference 
MOLN-D-19-01111-R3

1 mouse brain atlas pictures are presented to show the exact region where the cellular analysis was

2 performed (Supp. Fig. 8).

4 PKC-gamma translocates to the membrane preferentially after trace but not delay fear

5 compromise NR1-dependent plasticity.

\section{conditioning}

Hippocampal PKC-gamma has been described to translocate from the cytosol to the membrane after spatial learning [29] and context fear conditioning training [17]. We focused in the detection of hippocampal PKC-gamma translocation after trace and delay fear conditioning, following the same training paradigms as in Figure 5. For this purpose, membrane-enriched and cytosolic hippocampal fractions were prepared from samples obtained 30 min after training. Membraneenriched fraction analysis revealed a significant amount of PKC-gamma only in mice that went through the trace fear conditioning, but not after delay fear conditioning training or in control mice, exposed to the same environment (conditioning chamber) and auditory stimulus, but without unconditioned stimulus (footshock) (Fig. 6a). No significant differences were observed in the detection of PKC-gamma between all three experimental conditions in the cytosolic fraction (Fig. 6b), indicating that only a small fraction of hippocampal PKC-gamma pool is recruited to the membrane after the trace fear conditioning training. This membrane targeting of PKC-gamma could be related to alterations in NR1 signaling since we found that in hippocampal whole solubilized samples there is a significant difference in the phosphorylation level of the NR1 subunit at Ser890 (Supp. Fig. 9), a residue preferentially phosphorylated by PKC activity [19] when we compared PKC-gamma KO mice to WT controls. This result indicates that PKCgamma removal partially jeopardizes the overall phosphorylation of this residue and may 


\section{Discussion}

2 Our study reveals that the PKC-gamma KO mice show significant deficits in short-term forms of

3 memory, for which the long-term forms are completely preserved pointing to an independent

4 mechanistic regulation of both memory ranges derived from the same training episode. The hippocampal STM disturbances in PKC-gamma KO mice were concomitant with alterations in

6 c-Fos expression in the hippocampus induced by the encoding of a trace, but not by a delay, fear

7 conditioned memory.

8 The PKC family of kinases is a relevant group of enzymes important for learning and memory

9 [8]. There is much interest in the identification of specific functions associated to otherwise apparently redundant PKC isoforms, which in many occasions have overlapping expression

11 patterns $[14,30]$. Isoform specification has been previously studied through the use of genetic 12 deletion of a single isoform gene. Indeed, mice lacking the gene encoding PKC-beta showed 13 significant deficits in fear conditioning paradigms, which were not accompanied by detectable alterations in synaptic plasticity [31]. The genetic deletion of PKC-gamma resulted in mild alterations in spatial learning and fear conditioning [21] with significant reductions in hippocampal LTP, although other forms of hippocampal synaptic plasticity (including hippocampal long-term depression and paired-pulse facilitation) remained comparable to those in WT mice [15]. Notably, our study shows that PKC-gamma deletion did not lead to compensation through the expression of other functionally homologous isoforms in the hippocampus including alpha, beta I, beta II, epsilon, eta, delta and theta.

21 Our behavioral data clearly reveals that PKC-gamma KO mice present specific STM deficits in tasks where there is a significant contribution of the hippocampal activity. A significant deficit in spatial working memory compared to WT mice was detected in two conformations, the Tmaze and the Y-maze. Performance of correct alternations in this task is associated to specific temporal patterns of theta oscillations between the prefrontal cortex and the hippocampus [32], pointing to potential deficits in such interaction between brain areas in PKC-gamma KO mice, 
1 since they showed close to chance alternation values. In addition, our evaluation of long-term

2 spatial learning in the Barnes maze only revealed mild differences between genotypes, much

3 similar to the findings previously obtained by others with the same mouse model using the Morris

4 water maze [21, 33]. When fear memory was assessed in one of these previous studies, they

5 found a mild deficit in context-dependent fear conditioning LTM using a paradigm with several

6 footshock pairings [21]. This result is in contrast with the proper LTM performance we found

7 after a single pairing in our context recognition paradigm. Indeed, we found that our training

8 paradigm using one single pairing was clearly impaired in PKC-gamma KO mice when memory

9 was assessed $1 \mathrm{~h}$ and $3 \mathrm{~h}$ after conditioning. To further characterize the relevance of PKC-gamma

10 deletion in fear memory performance, we took advantage of the different neurobiological

11 substrates underlying the trace and delay fear conditioning paradigms [26]. These are similar

12 tasks, just differing in the trace period between the conditioned (auditory stimulus) and

13 unconditioned stimuli (single footshock). Previous studies have described a particular role of the

14 amygdala and the hippocampus in these fear conditioning paradigms. Indeed, the inactivation of

15 the amygdala produced deficits in delay, but not in trace fear conditioning, while the hippocampal

16 inactivation produced the opposite effect [26, 34, 35]. Moreover, other brain regions would also

17 be involved since the inactivation of the prelimbic cortex abolished fear expression [36]. Given

18 that PKC-gamma KO mice had a significant deficit in short-term trace fear conditioning, but no

19 alteration in short-term delay fear conditioning, the differences in the cellular outcome of both

20 training protocols were explored in specific brain areas relevant for STM performance

21 specifically during the acquisition phase. We studied c-Fos expression, a marker of neuronal

22 activity [37] that predicts memory acquisition [38, 39] and is a commonly used approach for the

23 study of memory engram cells [40] since its promoter can be used to tag neurons active during a

24 learning process [41]. These engrams or neuronal ensembles for fear memory have been

25 identified in the dentate gyrus of the hippocampus [28], the basolateral amygdala [41] and the 26 prefrontal cortex [42], where the modulation of the activity of these cells expressing c-Fos may 
1 alter memory-associated behaviors [43, 44]. Our results showed that PKC-gamma KO mice

2 exposed to the hippocampal-dependent trace fear conditioning protocol presented a lower

3 number of c-Fos-positive cells than WT mice in the dentate gyrus, but not in the basolateral

4 amygdala or the prelimbic cortex. Although in another timeframe, and limited to the behavioral

5 paradigm we used, these data are parsimonious with a model previously proposed suggesting that

6 memory engram cells are rapidly formed in the hippocampus, the basolateral amygdala and

7 prefrontal cortex during the acquisition of a fear conditioning memory [45]. Then, in recent recall, engrams in the basolateral amygdala and hippocampus drive the behavior, while those of the prefrontal cortex remain less involved. However, in remote recall, engrams in the hippocampus become less relevant while prefrontal cortex engrams gain relevance, driving the behavior together with those of the basolateral amygdala. Therefore, although our cellular study of c-Fos is limited to the acquisition phase of the cued fear conditioning paradigms, our results on the dentate gyrus of the hippocampus suggest that PKC-gamma signaling would be key for proper hippocampal encoding of memory. In this regard, the study of c-Fos expression after context fear conditioning or after memory retrieval could be relevant next steps to further assess the role of PKC-gamma signaling for recent or remote recall on hippocampal-dependent memories.

We cannot totally discard the possibility that the behavioral responses in PKC-gamma KO mice are related to more broad alterations in brain circuits due to the absence of PKC-gamma during neurodevelopment. Nevertheless, the fact that the PKC-gamma KO phenotype was restricted to alterations in specific STM tasks, indicates that the differences in STM performance were probably related to specific roles of PKC-gamma signaling than caused by general neurodevelopmental variations. In addition, the PKC-gamma KO phenotype was somewhat reminiscent of the differential effect of acute low doses of the non-specific PKC inhibitor chelerythrine on novel object-recognition memory described elsewhere [46]. When chelerythrine effect was assessed shortly after familiarization $(3 \mathrm{~h})$, there was a significant deficit in memory 
1 performance that was not observed when the effect was assessed $24 \mathrm{~h}$ later. Indeed, other

2 signaling pathways have been specifically associated to LTM, such as the 3 mammalian/mechanistic target of rapamycin (mTOR) pathway, or the translation machinery, as novel object-recognition LTM, but not STM, is sensitive to the inhibition of both mechanisms with temsirolimus or anisomycin, respectively [46].

6 We also observed that PKC-gamma translocates to the membrane preferentially after trace fear 7 conditioning training. This result reinforces previous data observed after context fear 8 conditioning [17], and further strengthens the role PKC-gamma activity may play in hippocampal dependent tasks. Notably, we also found that context fear conditioning performance was also affected in PKC-gamma KO mice when STM was assessed. The lack of PKC-gamma activity in

11 the membrane compartment in memory tasks with a strong hippocampal engagement could affect 12 the phosphorylation of key elements for synaptic plasticity such as NMDA receptors [47]. While 13 other phosphorylation-sensitive residues on NR1, such as Ser896 and Ser897, were similarly phosphorylated in WT and PKC-gamma KO samples (data not shown), we found that the NR1 Ser890 phosphorylation was diminished, in basal conditions, in the PKC-gamma KO mice. The phosphorylation of Ser890 has been previously related to PKC-gamma [19, 48]. This residue was previously found to affect NR1 intracellular and membrane localization, as exemplified in a 18 heterologous expression system [49]. Notably, NMDA receptors have been consistently involved in memory formation, including fear learning $[19,50,51]$, and the diminished phosphorylation of Ser890 in NR1 subunits in the hippocampus of PKC-gamma KO mice could be related to the 21 impaired hippocampal encoding observed in different memory tasks in PKC-gamma KO 22 animals.

23 Together, our data reveal the differential effect of PKC-gamma genetic deletion in memory 24 performance related to the time of recall in hippocampal-dependent memory tests. Notably, we found a significant dysfunction of PKC-gamma $\mathrm{KO}$ mice in hippocampal-dependent memory tests when recall was performed at short times (before $3 \mathrm{~h}$ of training) but not when recall was 
1 assessed at later times. This result strongly suggests parallel encoding of memory for short-term

2 and long-term usage, where PKC-gamma activity would be specifically involved in the

3 mechanisms for hippocampus-engaging short-lived memory forms.

Ethical approval:

"All applicable international, national, and/or institutional guidelines for the care and use of animals were followed."

\section{Acknowledgements}

9 We thank Dulce Real and Francisco Porrón for expert technical assistance and the Laboratory of 10 Neuropharmacology-NeuroPhar for helpful discussion. Predoctoral fellowship by FPI 11 (MINEICO/FEDER, EU) (LG-L). Predoctoral fellowship from the Spanish Ministry of 12 Education (AB-G). This work was supported by the Ministerio de Economía, Innovación y 13 Competitividad (MINECO) [\#BFU2015-68568-P to A.O., \#SAF2017-84060-R to R.M.]; the 14 Instituto de Salud Carlos III [\#RD16/0017/0020 to R.M.]; the Ministerio de Ciencia, Innovación 15 y Universidades [\# RTI2018-099282-B-I00 (AEI/FEDER/UE) to A.O.]; the Generalitat de 16 Catalunya [2017SGR-669 to R.M.]; the ICREA (Institució Catalana de Recerca i Estudis 17 Avançats) Academia to A.O. and R.M.; Grant "Unidad de Excelencia María de Maeztu", funded by the MINECO [\#MDM-2014-0370]; PLAN E (Plan Español para el Estímulo de la Economía y el Empleo). FEDER funding is also acknowledged.

\section{Conflict of interests:}

All authors report no biomedical financial interests or potential conflicts of interest. 


\section{$1 \quad$ Figure legends}

2 Figure 1. PKC isoform expression in the hippocampus of PKC-gamma KO mice. Replicates

3 of hippocampal samples (20 $\mu \mathrm{g}$ protein/well) from WT and PKC-gamma KO animals were run

4 in parallel and membrane replicates were incubated with PKC isoform-specific antibodies to

5 independently detect the conventional isoforms The detection of PKC-gamma was performed as

6 a control. No differences were found between WT and KO mice in the other PKC isoforms. (a) PKC gamma $(\mathrm{n}=6-7)[\mathrm{F}(1,11)=49.493, p<0.001],(\mathbf{b})$ alpha $(\mathrm{n}=6-7)[\mathrm{F}(1,11)=2.409, p$ detection of PKC-gamma protein in CA1 (stratum radiatum and stratum oriens) and dentate gyrus (especially hilus and inner molecular layer) of the hippocampus was notably higher in WT

mice compared to PKC-gamma KO mice. Scale bar $150 \mu \mathrm{m}$. Data are expressed as mean \pm s.e.m. $* * * \mathrm{p}<0.001$ (PKC-gamma KO compared to WT).

Figure 2. Spatial memory performance was evaluated in the PKC-gamma KO mice. Spatial STM was studied in the PKC-gamma KO mice (a-b) compared to WT controls in two different shaped mazes, $(\mathbf{a})$ the T-maze $(\mathrm{n}=11-16)[\mathrm{F}(1,25)=6.144, p<0.05]$ and $(\mathbf{b})$ the $\mathrm{Y}$-maze $(\mathrm{n}=$ 7-11) $[\mathrm{F}(1,16)=22.933, p<0.001]$. (c-d) Spatial memory was studied using the Barnes Maze task $(n=7-11)$. The percentage of time spent in the target zone was analyzed, demonstrating differences between genotypes $[(\mathbf{c}) 24 \mathrm{~h}: \mathrm{F}(1,16)=6.882, p<0.05 ;(\mathbf{d}) 7 \mathrm{~d}: \mathrm{F}(1,16)=5.022$, $p<0.05]$. (c) At spatial LTM test $(24 \mathrm{~h})$, the $\%$ of time in the target quadrant in WT (Target vs $-1[\mathrm{~F}(1,12)=31.03, p<0.001]$, Target vs $1[\mathrm{~F}(1,12)=34.953, p<0.001]$, Target vs Opposite $[\mathrm{F}(1,12)=34.331, p<0.001])$ and PKC-gamma KO (Target vs $-1[\mathrm{~F}(1,20)=27.248, p<$ 0.001], Target vs $1[\mathrm{~F}(1,20)=32.081, p<0.001]$, Target vs Opposite $[\mathrm{F}(1,20)=22.603, p<$ 
$10.001]$ ) was higher than in the other quadrants. (d) In remote test (7 d), the \% of time was also

2 higher in the target quadrat for WT (Target vs $-1[\mathrm{~F}(1,12)=14.613, p<0.01]$, Target vs 1

$3[\mathrm{~F}(1,12)=17.825, p<0.01]$, Target vs Opposite $[\mathrm{F}(1,12)=13.932, p<0.01])$ and PKC-

4 gamma mice (Target vs $-1[\mathrm{~F}(1,20)=4.48, p<0.05]$, Target vs $1[\mathrm{~F}(1,20)=27.872, p<$

0.001], Target vs Opposite $[\mathrm{F}(1,20)=31.604, p<0.001])$. Data are expressed as mean \pm s.e.m.

$* \mathrm{p}<0.05, * * * \mathrm{p}<0.001$ (PKC-gamma KO compared to WT). \&\& $\mathrm{p}<0.01, \& \& \& \mathrm{p}<0.001$

(in WT compared with target). \# $\mathrm{p}<0.05$, \#\#\# $\mathrm{p}<0.001$ (in PKC-gamma KO compared with target).

Figure 3. Short-term, but not long-term non-emotional memories are affected in PKC-

gamma KO mice. (a) Short-term $(10 \min (\mathrm{n}=9-10)[\mathrm{F}(1,17)=24.115, p<0.001]$ and/or $3 \mathrm{~h}$

$11(\mathrm{n}=7-8) \quad[\mathrm{F}(1,13)=6.787, p<0.05])$ and long-term memory $(6 \mathrm{~h}(\mathrm{n}=7-8)[\mathrm{F}(1,13)=$

2.539, $p=0.135], 24 \mathrm{~h}(\mathrm{n}=7-8)[\mathrm{F}(1,20)=0.0001, p=0.992]$ and $48 \mathrm{~h}(\mathrm{n}=7-11)[\mathrm{F}(1,16)=$

$0.115, p=0.739])$ were studied in the novel object-recognition test. (b) Short-term $(3 \mathrm{~h}(\mathrm{n}=9$ -

10) $[\mathrm{F}(1,16)=23.749, p<0.001])$ and long-term $(24 \mathrm{~h}(\mathrm{n}=9-10) \quad[\mathrm{F}(1,15)=1.759, p=$

0.205]) memory were also studied in the novel place-recognition test comparing the PKC-gamma

KO mice with WT mice. (c) No differences were observed between the PKC-gamma KO and wild-type mice when locomotion was studied $(n=7-11)$ [Number of beam breaks: $F(1,16)=$ $0.063, \mathrm{p}=0.805 ;$ Number of rearings $\mathrm{F}(1,16)=1.135, \mathrm{p}=0.305]$. Data are expressed as mean \pm s.e.m. $* \mathrm{p}<0.05, * * * \mathrm{p}<0.001(\mathrm{PKC}$-gamma KO compared to WT).

Figure 4. Hippocampal-dependent short-term emotional memories are impaired in the

21 PKC-gamma KO mice. Short-term and long-term memories were studied in the (a) context recognition test $[1 \mathrm{~h}(\mathrm{n}=7-8): \mathrm{F}(1,13)=5.236, p<0.05 ; 3 \mathrm{~h}(\mathrm{n}=14): \mathrm{F}(1,26)=5.314, p<$ $0.05 ; 24 \mathrm{~h}(\mathrm{n}=12-14): \mathrm{F}(1,24)=0.372, p=0.548]$, the $(\mathbf{b})$ trace fear conditioning test $[3 \mathrm{~h}(\mathrm{n}$ $24=8-10): \mathrm{F}(1,16)=13.385, p<0.01 ; 24 \mathrm{~h}(\mathrm{n}=8): \mathrm{F}(1,14)=0.892, p=0.361]$ and the $(\mathbf{c})$ delay fear conditioning test $[3 \mathrm{~h}(\mathrm{n}=6): \mathrm{F}(1,10)=0.013, p=0.910 ; 24 \mathrm{~h}(\mathrm{n}=7-13): \mathrm{F}(1,18)$

$26=0.203, p=0.657]$ comparing the PKC-gamma $\mathrm{KO}$ mice with the WT controls. (d) No 
1 differences were observed between the PKC-gamma $\mathrm{KO}$ and wild-type mice when nociception

2 was studied $(\mathrm{n}=10)$ [paw: $\mathrm{F}(1,36)=1.122, \mathrm{p}=0.297$; genotype: $\mathrm{F}(1,36)=1.106, \mathrm{p}=0.30$;

3 interaction: $\mathrm{F}(1,36)=0.107, \mathrm{p}=0.745]$. Data are expressed as mean \pm s.e.m. $* \mathrm{p}<0.05, * * * \mathrm{p}$

$4<0.001$ (PKC-gamma KO compared to WT).

5 Figure 5. c-Fos expression in the dentate gyrus of the hippocampus was altered in PKC-

6 gamma KO mice after trace fear conditioning. c-Fos quantification was performed in brain samples obtained $2 \mathrm{~h}$ after mice exposure to the trace or the delay fear conditioning protocol. This analysis was performed in different brain regions including (a) the dentate gyrus (DG) of the hippocampus $(\mathrm{n}=3-6)$ [conditioning protocol: $\mathrm{F}(2,22)=6.786, p<0.01$; genotype: $\mathrm{F}(1,22)$

$10=0.309, p=0.584$; interaction: $\mathrm{F}(2,22)=6.668, p<0.01]$, (b) the basolateral amygdala (BLA)

$11(\mathrm{n}=3-6)$ [conditioning protocol: $\mathrm{F}(2,22)=33.36, p<0.001$; genotype: $\mathrm{F}(1,22)=0.851, p=$ 0.366; interaction: $\mathrm{F}(2,22)=0.934, p=0.408]$ and $(\mathbf{c})$ the prelimbic cortex $(\mathrm{PL})(\mathrm{n}=2-6)$ [conditioning protocol: $\mathrm{F}(2,22)=28.093, p<0.001$; genotype: $\mathrm{F}(1,22)=2.514, p=0.127$; interaction: $\mathrm{F}(2,22)=1.143, p=0.337]$. Data are expressed as mean \pm s.e.m. $* \mathrm{p}<0.05, * * \mathrm{p}<$ $0.01, * * * \mathrm{p}<0.001$, (Trace or delay fear conditioning compared to control in WT mice), \# $\mathrm{p}<$ 0.05, \#\#\# p $<0.001$ (Trace or delay fear conditioning compared to control in PKC-gamma KO mice), \& p $<0.05$ (WT vs. PKC-gamma KO mice). Scale bar $200 \mu \mathrm{m}$.

Figure 6. Recruitment of PKC-gamma to the membrane compartment in the hippocampus after fear conditioning training. (a) In the membrane fraction, PKC-gamma isoform is significantly increased 30 min after trace fear conditioning compared to control subunit $(n=4)$ and delay groups subunit $(\mathrm{n}=4)$ [conditioning protocol: $\mathrm{F}(2,9)=21.048, p<0.001$ ]. (b) No differences were found between conditioning protocols in the cytosolic fraction neither after trace $(\mathrm{n}=4)$ or delay $(\mathrm{n}=4)$ [conditioning protocol: $\mathrm{F}(2,9)=1.098, p=0.374$ ] fear conditioning. conditioning protocol). 


\section{References}

1. Abel T, Lattal KM (2001) Molecular mechanisms of memory acquisition, consolidation and retrieval. Curr Opin Neurobiol 11:180-187. https://doi.org/10.1016/S0959-4388(00)00194-X

2. Cowan N (2009) What are the differences between long-term, short-term, and working memory? Prog Brain Res 6123:323-338. https://doi.org/10.1016/S0079-6123(07)00020-9

3. McClelland JL, McNaughton BL, O'Reilly RC (1995) Why there are complementary learning systems in the hippocampus and neocortex: insights from the successes and failures of connectionist models of learning and memory. Psychol Rev 102:419-457. https://doi.org/10.1037/0033-295X.102.3.419

4. Tse D, Langston RF, Kakeyama M, et al (2007) Schemas and memory consolidation. Science 316:76-82. https://doi.org/10.1126/science.1135935

5. McClelland JL (2013) Incorporating rapid neocortical learning of new schema-consistent information into complementary learning systems theory. J Exp Psychol Gen 142:1190-1210. https://doi.org/10.1037/a0033812

6. Squire LR, Genzel L, Wixted JT, Morris RG (2015) Memory consolidation. Cold Spring Harb Perspect Biol 7:a021766. https://doi.org/10.1101/cshperspect.a021766

7. Amadio M, Battaini F, Pascale A (2006) The different facets of protein kinases C: old and new players in neuronal signal transduction pathways. Pharmacol Res 54:317-325.

https://doi.org/10.1016/J.PHRS.2006.08.002

8. Sun MK, Alkon DL (2014) The "memory kinases": Roles of PKC isoforms in signal processing and memory formation. Prog Mol Biol Transl Sci 122:31-59. https://doi.org/10.1016/B978-0-12420170-5.00002-7

9. Van Der Zee EA, Luiten PGM, Disterhoft JF (1997) Learning-induced alterations in hippocampal PKC-immunoreactivity: A review and hypothesis of its functional significance. Prog Neuro-Psychopharmacology Biol Psychiatry 21:531-572. https://doi.org/10.1016/S02785846(97)00017-1

10. Mackay HJ, Twelves CJ (2007) Targeting the protein kinase C family: are we there yet? Nat Rev Cancer 7:554-562. https://doi.org/10.1038/nrc2168

11. Newton AC (1995) Protein Kinase C: Structure, function, and regulation. J Biol Chem 270:28495-28498. https://doi.org/10.1074/jbc.270.48.28495

12. Newton AC (2010) Protein kinase C: poised to signal. Am J Physiol Metab 298:E395-E402. https://doi.org/10.1152/ajpendo.00477.2009

13. Saito N, Kikkawa U, Nishizuka Y, Tanaka C (1988) Distribution of protein kinase C-like immunoreactive neurons in rat brain. J Neurosci 8:369-82. https://doi.org/10.1523/JNEUROSCI.08-02-00369.1988

14. Tanaka C, Saito N (1992) Localization of subspecies of protein kinase C in the mammalian central nervous system. Neurochem Int 21:499-512. https://doi.org/10.1016/01970186(92)90081-2

15. Abeliovich A, Chen C, Goda Y, et al (1993) Modified hippocampal long-term potentiation in PKC gamma-mutant mice. Cell 75:1253-1262. https://doi.org/10.1016/0092-8674(93)90613-u

16. Saito N, Yasuhito S (2002) Protein Kinase C gamma (PKC gamma): Function of neuron specific isotype. J Biochem 132:683-87. https://doi.org/10.1093/oxfordjournals.jbchem.a003274

17. Young E, Cesena T, Meiri KF, Perrone-Bizzozero NI (2002) Changes in protein kinase C (PKC) activity, isozyme translocation, and GAP-43 phosphorylation in the rat hippocampal formation after a single-trial contextual fear conditioning paradigm. Hippocampus 12:457-464. https://doi.org/10.1002/hipo.10015

18. Suen PC, Wu K, Xu JL, et al (1998) NMDA receptor subunits in the postsynaptic density of rat brain: Expression and phosphorylation by endogenous protein kinases. Mol Brain Res. https://doi.org/10.1016/S0169-328X(98)00157-0

19. Sánchez-Pérez AM, Felipo V (2005) Serines 890 and 896 of the NMDA receptor subunit NR1 are differentially phosphorylated by protein kinase $\mathrm{C}$ isoforms. Neurochem Int. https://doi.org/10.1016/j.neuint.2005.04.011

20. Wang JQ, Guo ML, Jin DZ, et al (2014) Roles of subunit phosphorylation in regulating glutamate receptor function. Eur J Pharmacol. https://doi.org/10.1016/j.ejphar.2013.11.019

21. Abeliovich A, Paylor R, Chen C, et al (1993) PKCgamma mutant mice exhibit mild deficits in 
spatial and contextual learning. Cell 75:1263-71. https://doi.org/10.1016/0092-8674(93)90614-V

22. Sunyer B, Patil S, Höger H, Luber G (2007) Barnes maze, a useful task to assess spatial reference memory in the mice. Protoc Exch 1-12. https://doi.org/10.1038/nprot.2007.390

23. Puighermanal E, Marsicano G, Busquets-garcia A, et al (2009) Cannabinoid modulation of hippocampal long-term memory is mediated by mTOR signaling. Nat Neurosci 12:1152-8. https://doi.org/10.1038/nn.2369

24. Busquets-Garcia A, Puighermanal E, Pastor A, et al (2011) Differential role of anandamide and 2-arachidonoylglycerol in memory and anxiety-like responses. Biol Psychiatry 70:479-486. https://doi.org/10.1016/j.biopsych.2011.04.022

25. Ozaita A, Puighermanal E, Maldonado R (2007) Regulation of PI3K / Akt / GSK-3 pathway by cannabinoids in the brain. 1105-1114. https://doi.org/10.1111/j.1471-4159.2007.04642.x

26. Raybuck JD, Matthew Lattal K (2011) Double dissociation of amygdala and hippocampal contributions to trace and delay fear conditioning. PLoS One 6:8-12. https://doi.org/10.1371/journal.pone.0015982

27. Tanaka KZ, McHugh TJ (2018) The hippocampal engram as a memory index. J Exp Neurosci 12:. https://doi.org/10.1177/1179069518815942

28. Liu X, Ramirez S, Pang PT, et al (2012) Optogenetic stimulation of a hippocampal engram activates fear memory recall. Nature 484:381-385. https://doi.org/10.1038/nature11028

29. Douma BRK, Van der Zee EA, Luiten PGM (1998) Translocation of protein kinase C $\gamma$ occurs during the early phase of acquisition of food rewarded spatial learning. Behav Neurosci 112:496-501. https://doi.org/10.1037/0735-7044.112.3.496

30. Naik MU, Benedikz E, Hernandez I, et al (2000) Distribution of protein kinase $M \zeta$ and the complete protein kinase $\mathrm{C}$ isoform family in rat brain. J Comp Neurol 426:243-258. https://doi.org/10.1002/1096-9861(20001016)426:2<243::AID-CNE6>3.0.CO;2-8

31. Weeber EJ, Atkins CM, Selcher JC, et al (2000) A role for the $\beta$ isoform of protein kinase C in fear conditioning. J Neurosci 20:5906-5914. https://doi.org/10.1523/jneurosci.20-16-05906.2000

32. Crouch B, Sommerlade L, Veselcic P, et al (2018) Detection of time-, frequency-And directionresolved communication within brain networks. Sci Rep 8:. https://doi.org/10.1038/s41598-01819707-1

33. Su Q, Zhang H, Dang S, et al (2019) Hippocampal protein kinase C gamma signaling mediates the impairment of spatial learning and memory in prenatally stressed offspring rats. Neuroscience 19:30447-6. https://doi.org/10.1016/j.neuroscience.2019.06.030

34. Bangasser DA, Waxler DE, Santollo J, Shors TJ (2012) Trace conditioning and the hippocampus: the importance of contiguity. J Neurosci 26:8702-8706. https://doi.org/10.1523/JNEUROSCI.1742-06.2006.Trace

35. Burman MA, Simmons CA, Hughes M, Lei L (2014) Developing and validating trace fear conditioning protocols in C57BL/6 mice. J Neurosci Methods. https://doi.org/10.1016/j.jneumeth.2013.11.005

36. Sierra-Mercado D, Padilla-Coreano N, Quirk GJ (2011) Dissociable roles of prelimbic and infralimbic cortices, ventral hippocampus, and basolateral amygdala in the expression and extinction of conditioned fear. Neuropsychopharmacology 36:529-538. https://doi.org/10.1038/npp.2010.184

37. Morgan JI, Curran T (1986) Role of ion flux in the control of c-fos expression. Nature 322:552555. https://doi.org/10.1038/322552a0

38. Lüscher Dias T, Fernandes Golino H, Moura de Oliveira VE, et al (2016) c-Fos expression predicts long-term social memory retrieval in mice. Behav Brain Res 313:260-271. https://doi.org/10.1016/j.bbr.2016.07.030

39. Milanovic S, Radulovic J, Laban O, et al (1998) Production of the Fos protein after contextual fear conditioning of C57BL/6N mice. Brain Res 784:37-47. https://doi.org/10.1016/S00068993(97)01266-3

40. Tonegawa S, Pignatelli M, Roy DS, Ryan TJ (2015) Memory engram storage and retrieval. Curr Opin Neurobiol 35:101-109. https://doi.org/10.1016/j.conb.2015.07.009

41. Reijmers LG, Perkins BL, Matsuo N, Mayford M (2007) Localization of a stable neural correlate of associative memory. Science 317:1230-1234. https://doi.org/10.1126/science.1143839

42. Zelikowsky M, Hersman S, Chawla MK, et al (2014) Neuronal Ensembles in Amygdala, Hippocampus, and Prefrontal Cortex Track Differential Components of Contextual Fear. J Neurosci 34:8462-8466. https://doi.org/10.1523/jneurosci.3624-13.2014 
43. Miyashita T, Kikuchi E, Horiuchi J, Saitoe M (2018) Long-Term Memory Engram Cells Are Established by c-Fos/CREB Transcriptional Cycling. Cell Rep 25:2716-2728.e3. https://doi.org/10.1016/j.celrep.2018.11.022

44. Ramirez S, Liu X, Lin PA, et al (2013) Creating a false memory in the hippocampus. Science 341:387-391. https://doi.org/10.1126/science.1239073

45. Smith LM, Tonegawa S, Ogawa SK, et al (2017) Engrams and circuits crucial for systems consolidation of a memory. Science 356:73-78. https://doi.org/10.1126/science.aam6808

46. Busquets-Garcia A, Gomis-González M, Salgado-Mendialduá V, et al (2018) Hippocampal Protein Kinase C Signaling Mediates the Short-Term Memory Impairment Induced by Delta9Tetrahydrocannabinol. Neuropsychopharmacology 43:1021-1031. https://doi.org/10.1038/npp.2017.175

47. Chen BS, Roche KW (2007) Regulation of NMDA receptors by phosphorylation. Neuropharmacology 53:362-368. https://doi.org/10.1016/j.neuropharm.2007.05.018

48. Takagi N, Besshoh S, Morita H, et al (2010) Metabotropic glutamate mGlu5 receptor-mediated serine phosphorylation of NMDA receptor subunit NR1 in hippocampal CA1 region after transient global ischemia in rats. Eur J Pharmacol. https://doi.org/10.1016/j.ejphar.2010.07.026

49. Tingley WG, Ehlers MD, Kameyama K, et al (1997) Characterization of Protein Kinase A and Protein Kinase C Phosphorylation of the. Mol Biol. https://doi.org/10.1074/jbc.272.8.5157

50. Maren S (2001) Neurobiology of Pavlovian Fear Conditioning. Annu Rev Neurosci. https://doi.org/10.1146/annurev.neuro.24.1.897

51. Martin SJ, Grimwood PD, Morris RGM (2000) Synaptic Plasticity and Memory: An Evaluation of the Hypothesis. Annu Rev Neurosci. https://doi.org/10.1146/annurev.neuro.23.1.649 


\section{Conventional Isoforms}
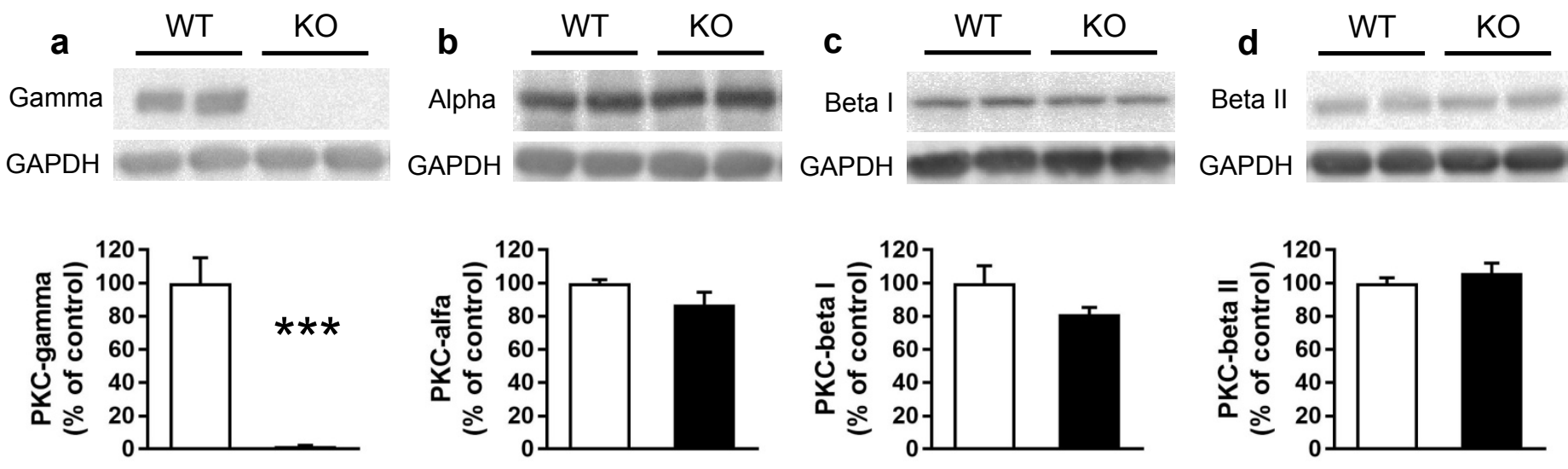

Novel Isoforms
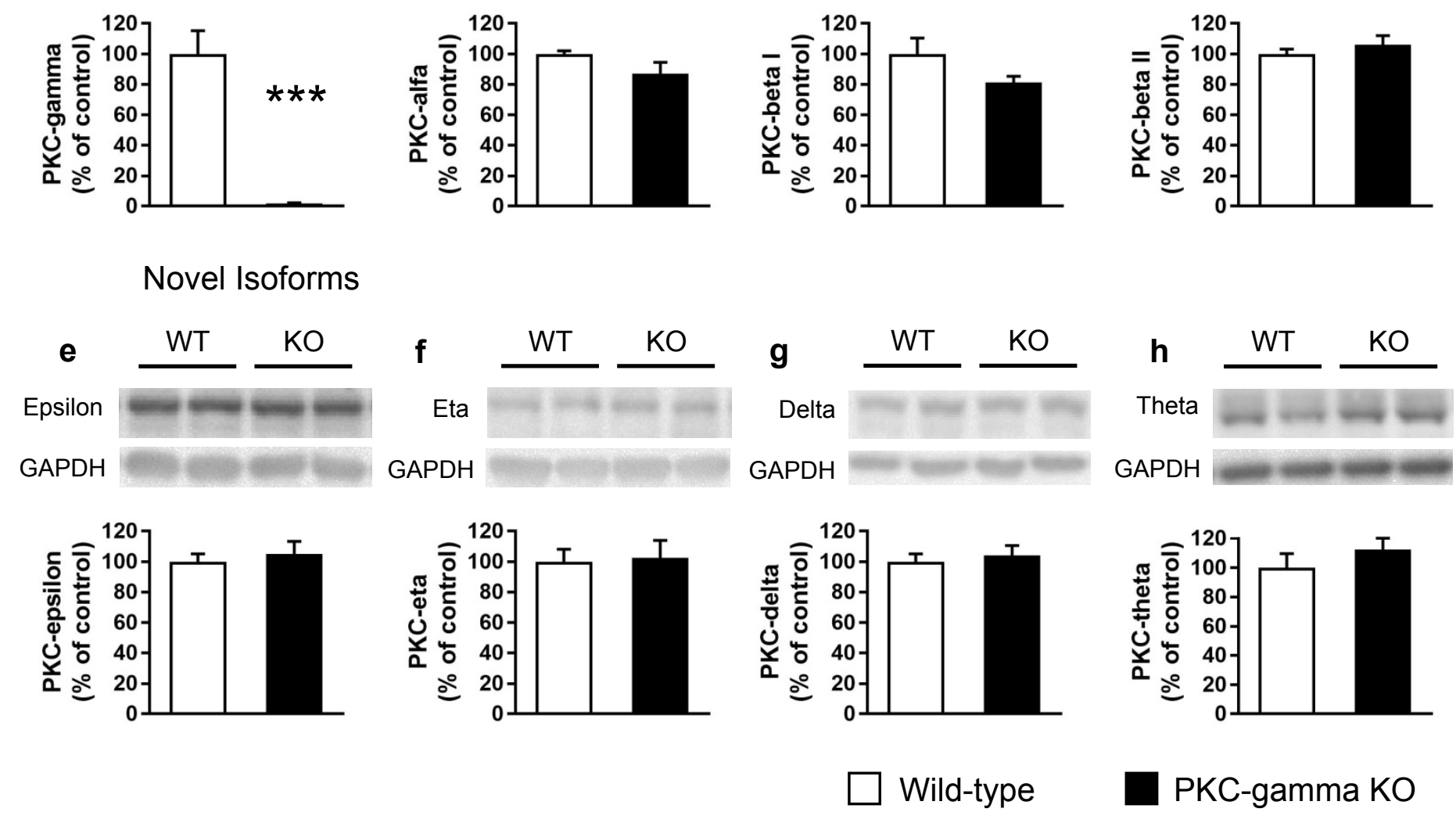

i

CA1

PKC-gamma

NeuN

PKC-gamma

NeuN
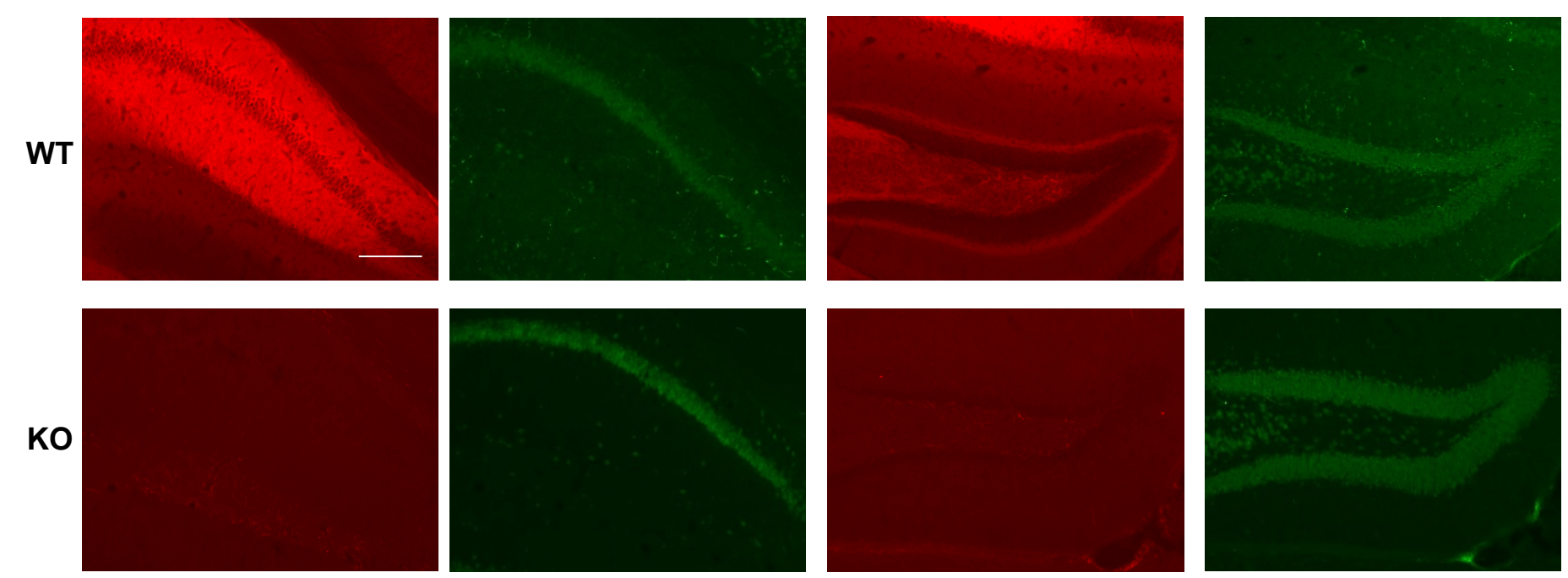

MOLN-D-19-01111-R3

Gomis-González et al. Figure 1 
a

T-maze

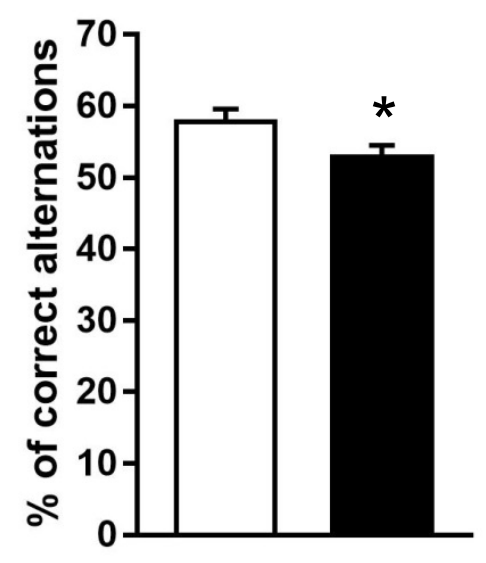

c Barnes-maze $24 \mathrm{~h}$

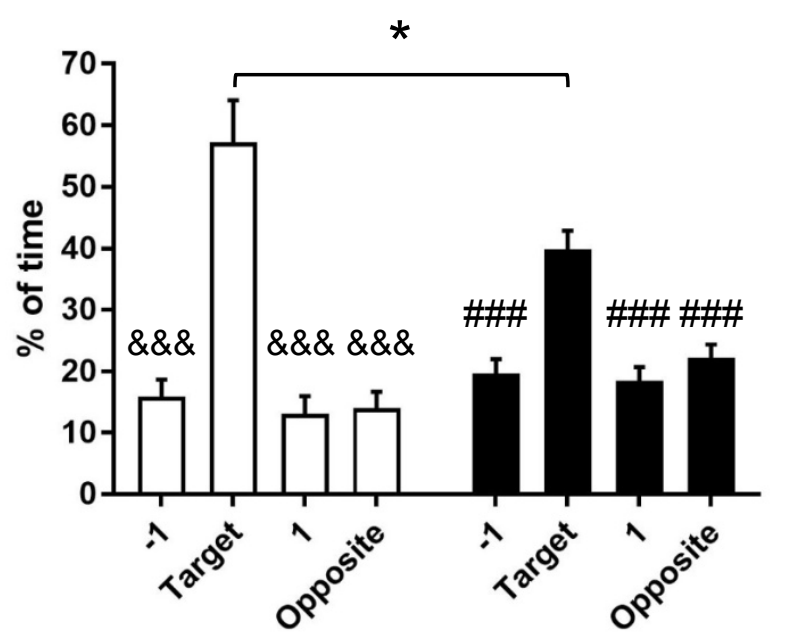

b
Y-maze

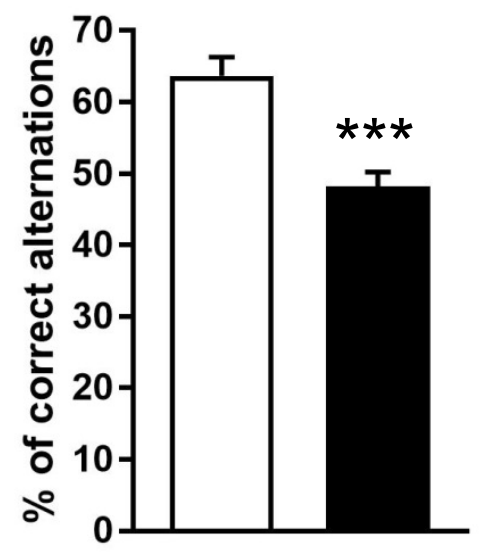

d Barnes-maze $7 \mathrm{~d}$

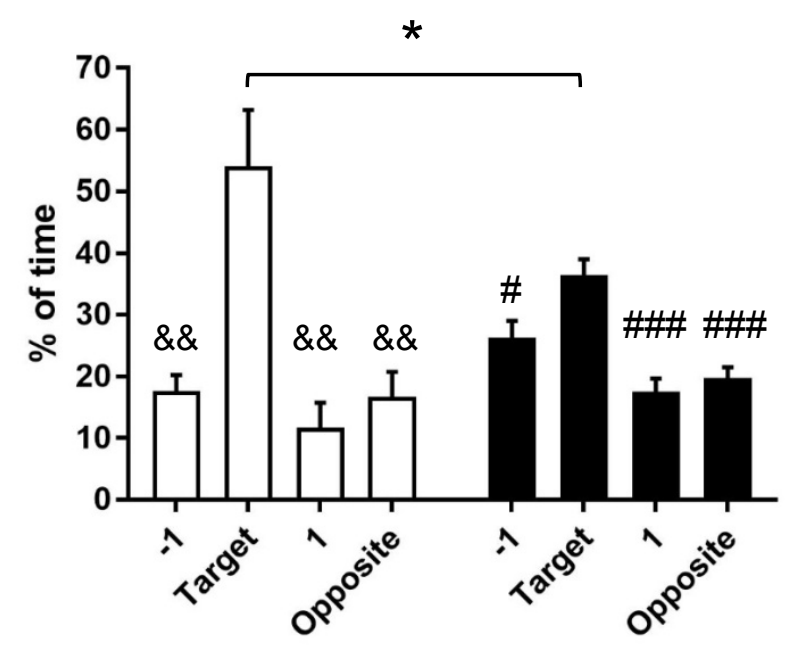

$\square$ Wild-type $\quad \square$ PKC-gamma KO

MOLN-D-19-01111-R3

Gomis-González et al. Figure 2 
a Novel Object Recognition

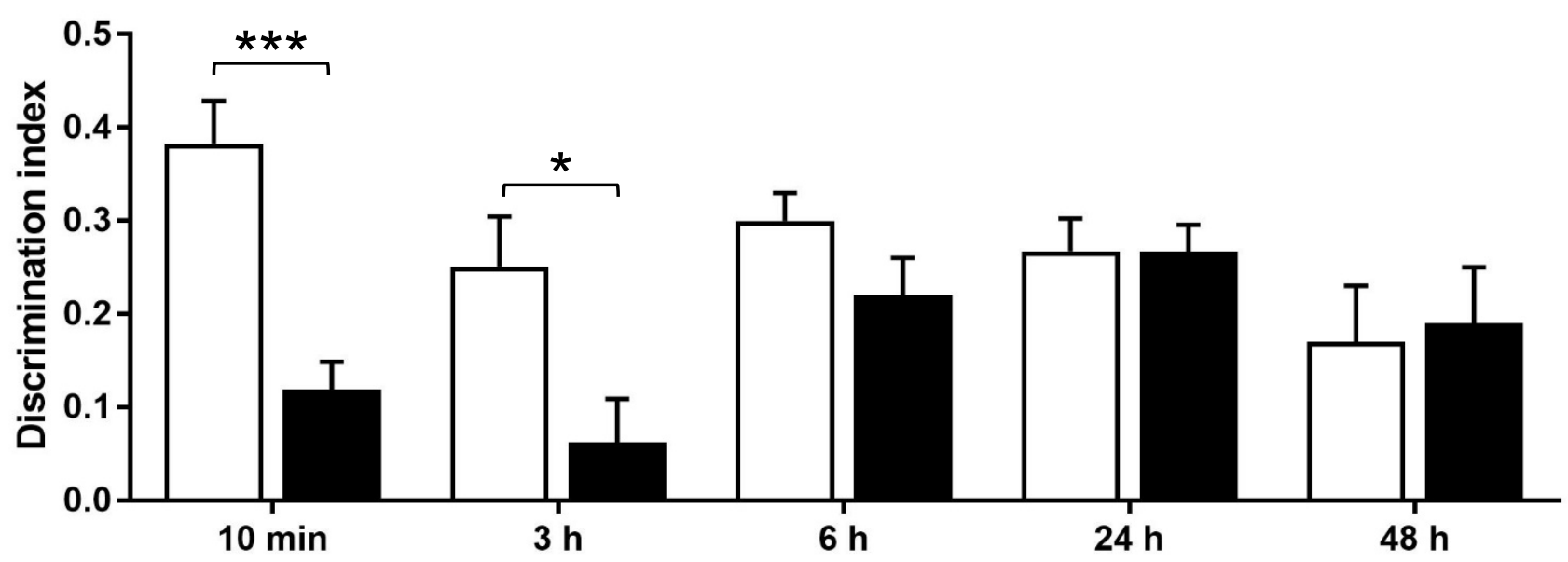

b Novel Place Recognition

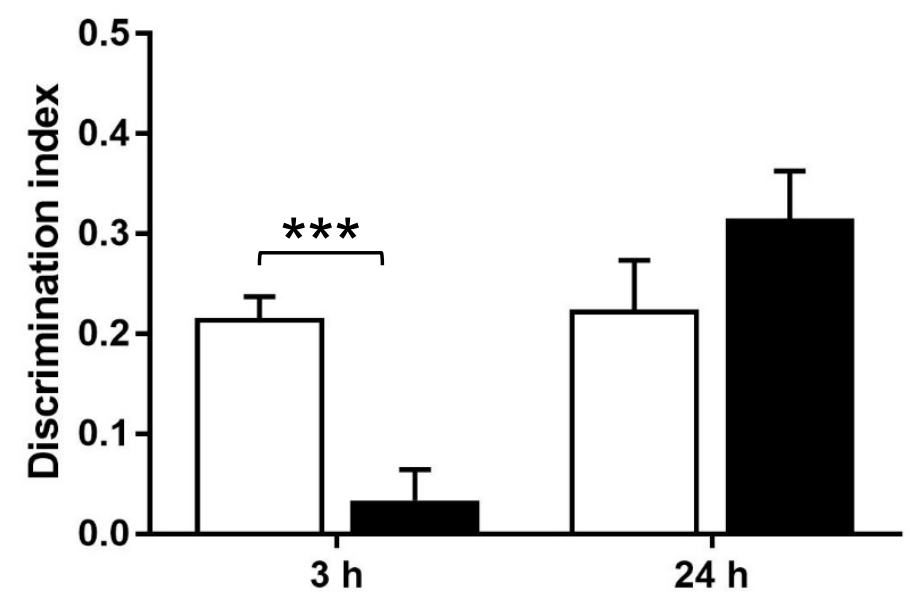

c Locomotor activity
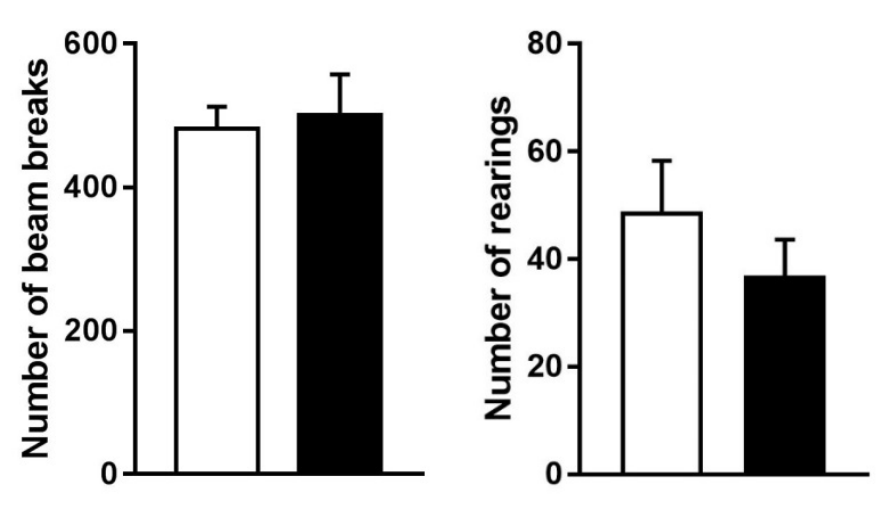

$\square$ Wild-type

DKC-gamma KO

MOLN-D-19-01111-R3

Gomis-González et al. Figure 3 
a

Context fear conditioning

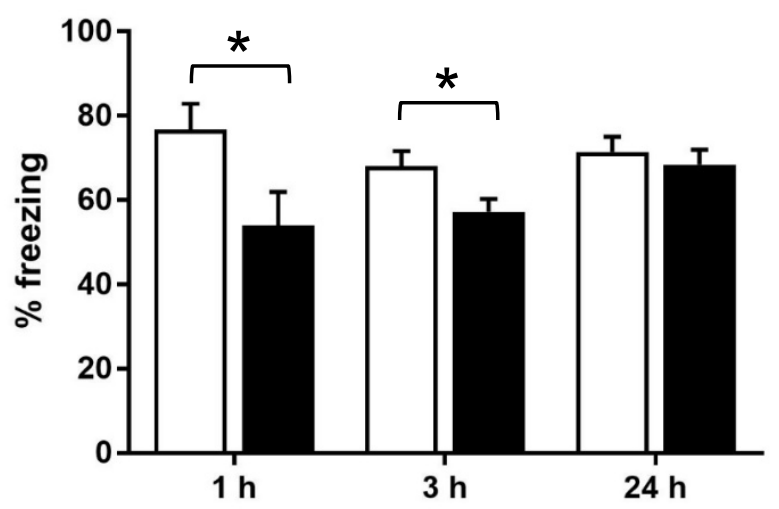

c Delay fear conditioning

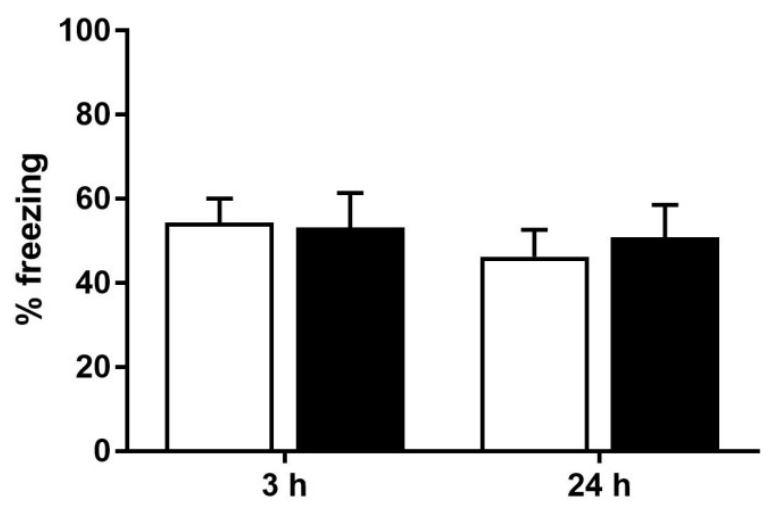

$\square$ Wild-type

PKC-gamma KO b Trace fear conditioning

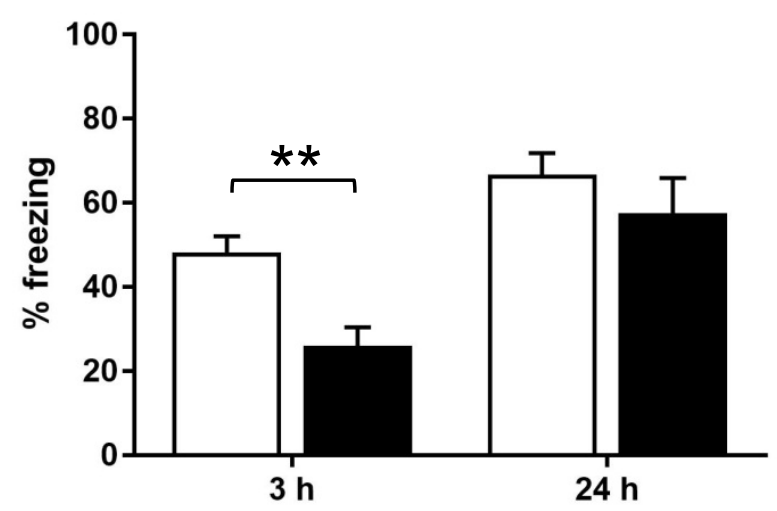

d Plantar test

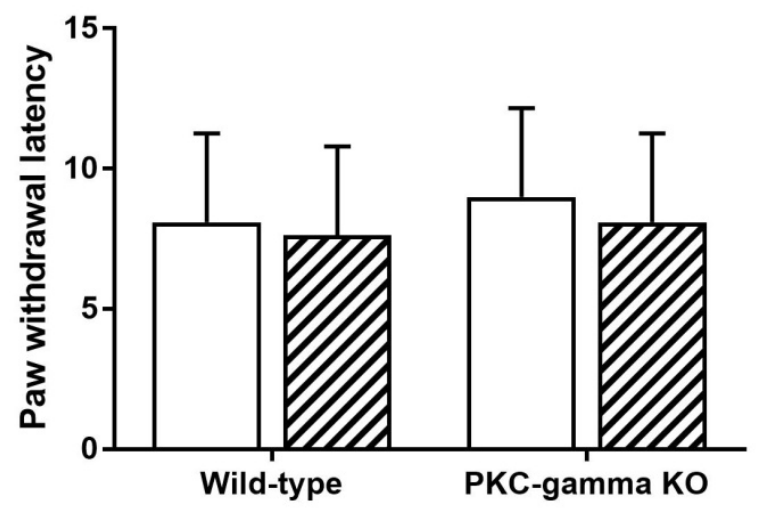

$\square$ Right paw

$\boldsymbol{Q}$ Left paw

MOLN-D-19-01111-R3

Gomis-González et al. Figure 4 
a

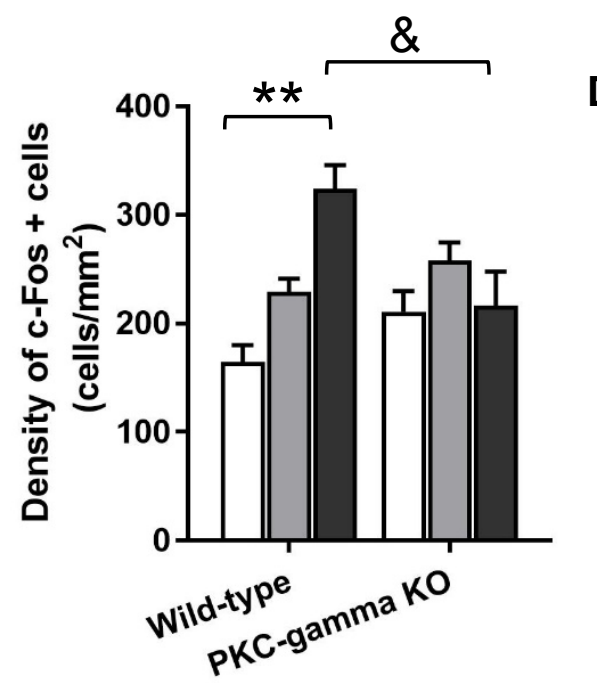

DG

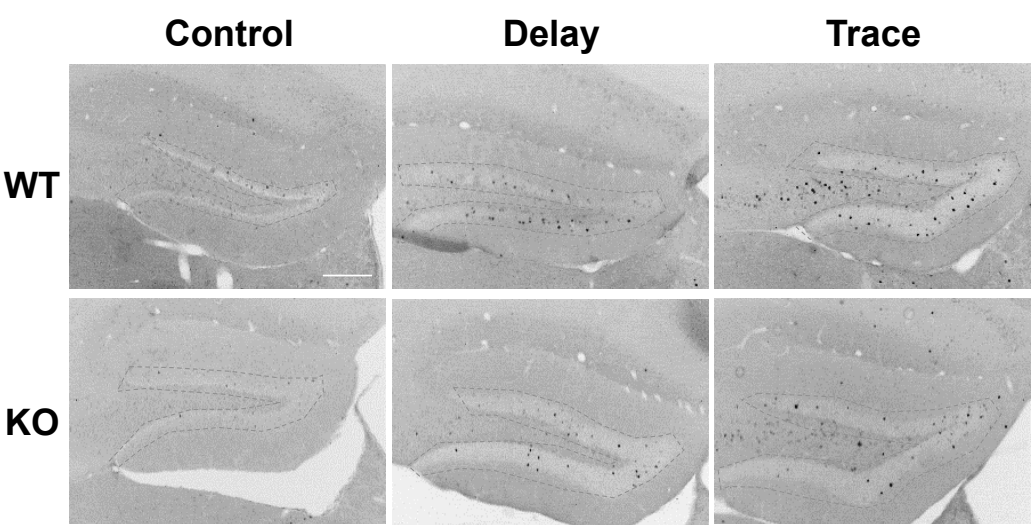

b

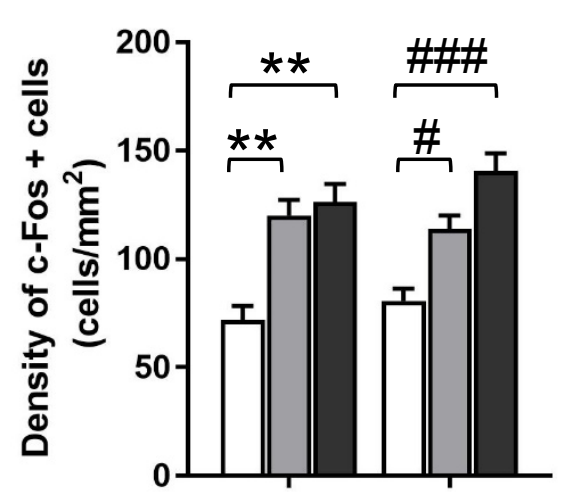

BLA

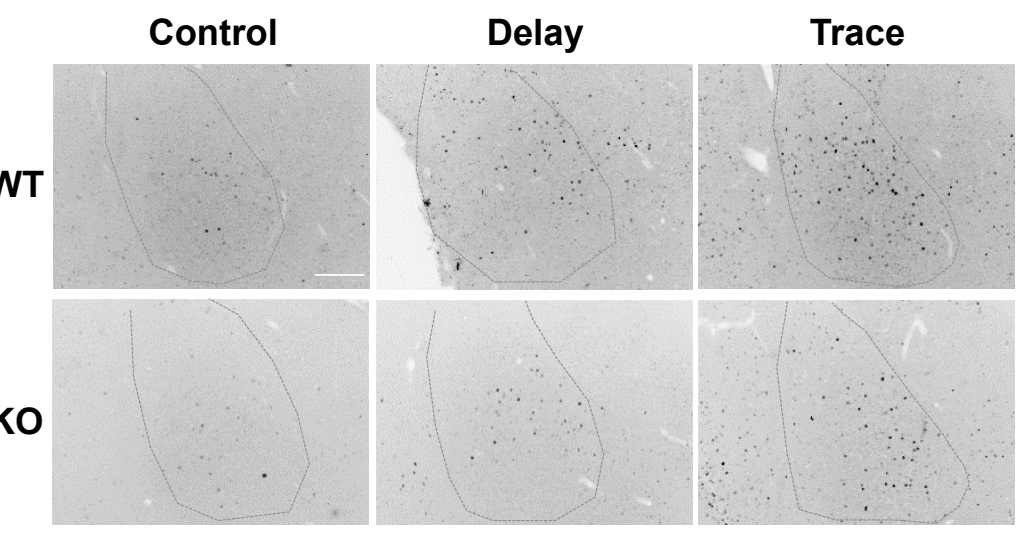
wild-type
pkC-gammako

C
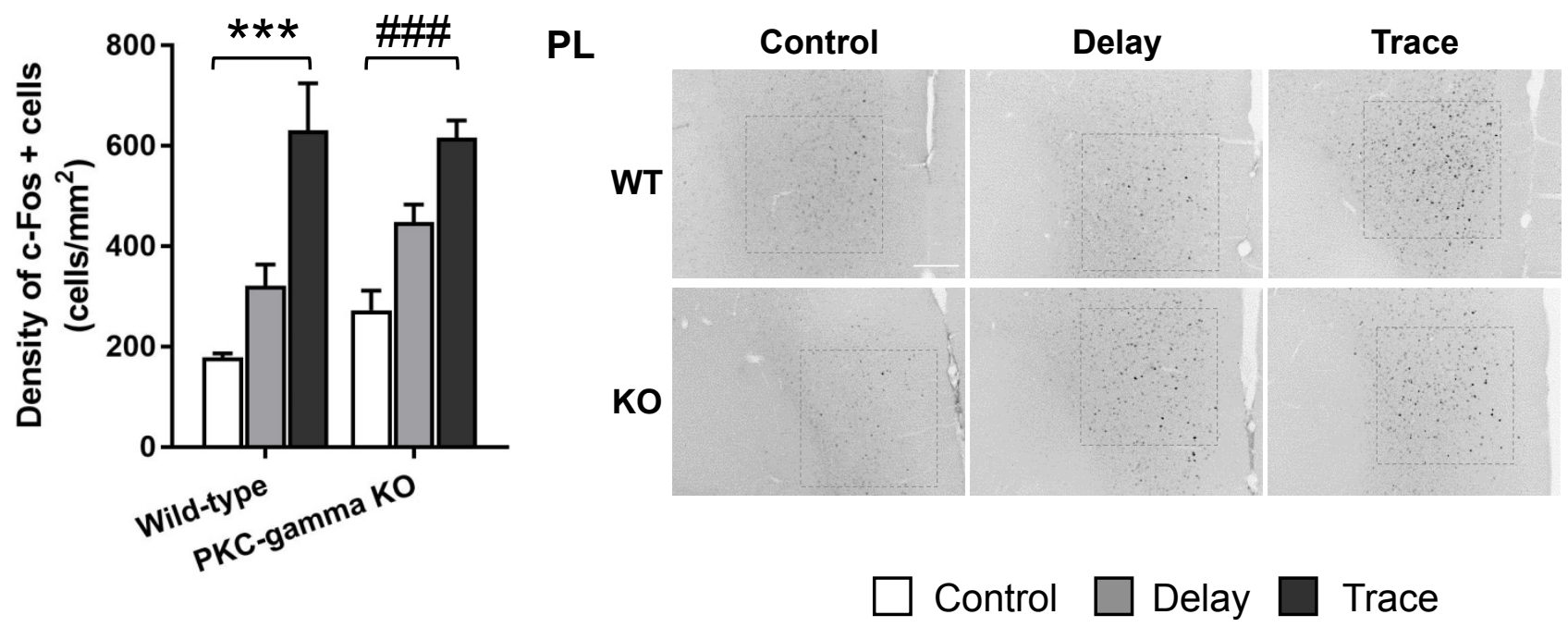

MOLN-D-19-01111-R3

Gomis-González et al. Figure 5 
Membrane fraction

a

PKC-

gamma

Ponceau

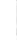

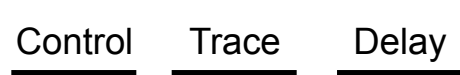

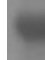
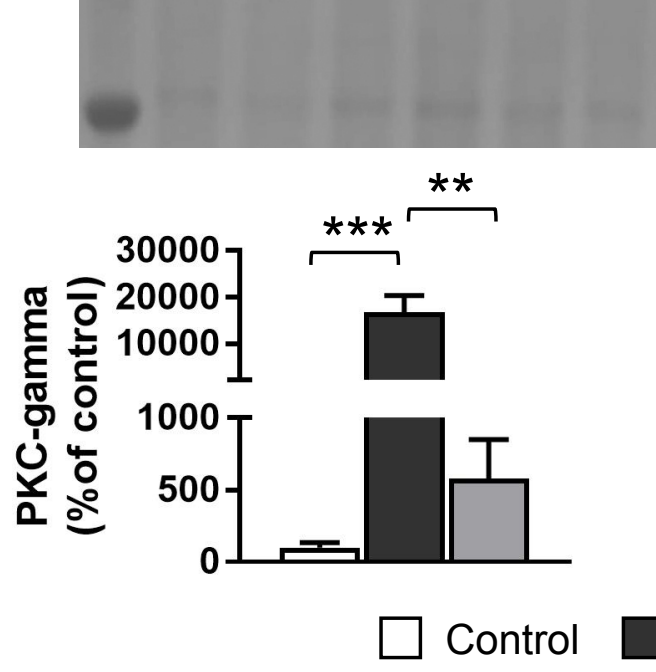

Cytosolic fraction

b Control Trace Delay

PKC-

gamma

GAPDH

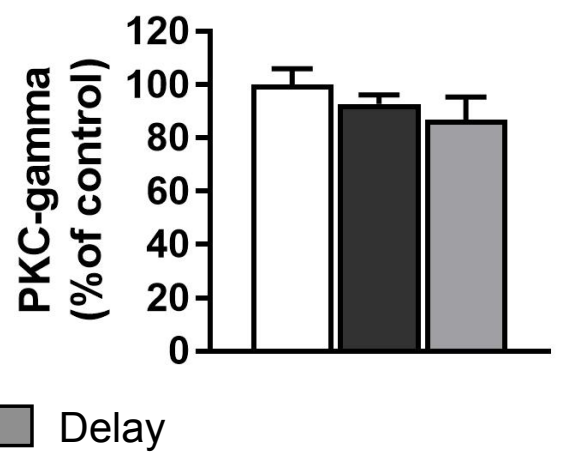

MOLN-D-19-01111-R3

Gomis-González et al. Figure 6 


\section{BARNES MAZE}
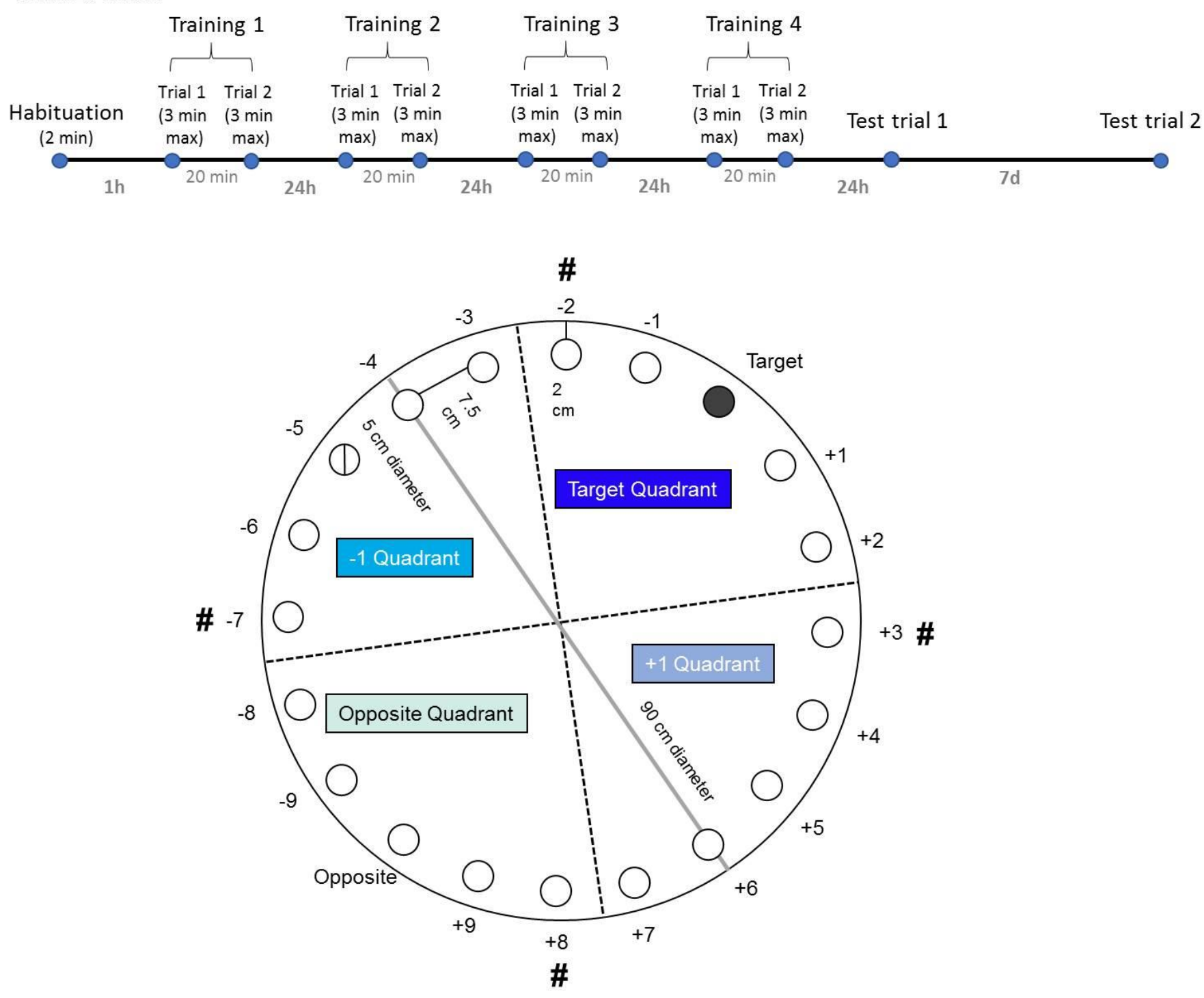

Supplementary Figure 1. Timeline and scheme of the Barnes maze task. Timeline of Barnes maze test indicating the training sessions and the time points when the tests were performed (Test Trial 1-recent spatial long-term memory; Test Trial 2-remote spatial long-term memory). The maze consists of a circular platform (90 cm diameter) with 20 equally spaced holes of $5 \mathrm{~cm}$ diameter separated by $7.5 \mathrm{~cm}$. Holes have a distance of $2 \mathrm{~cm}$ from the perimeter of the circular maze and numbered from +1 to +9 (on the right side of the target hole) and from -1 to -9 (on the left). There is also an opposite hole to the target hole. The maze is divided in 4 quadrants containing 5 holes each one: target quadrant (from -2 to +2 ), +1 quadrant (from +3 to +7 ), opposite quadrant (from +8 to -8 ) and -1 quadrant (from -7 to -3 ). In the limits of the quadrants there are different visual cues surrounding the maze (represented as \#) 


\section{A. NOVEL OBJECT RECOGNITION}

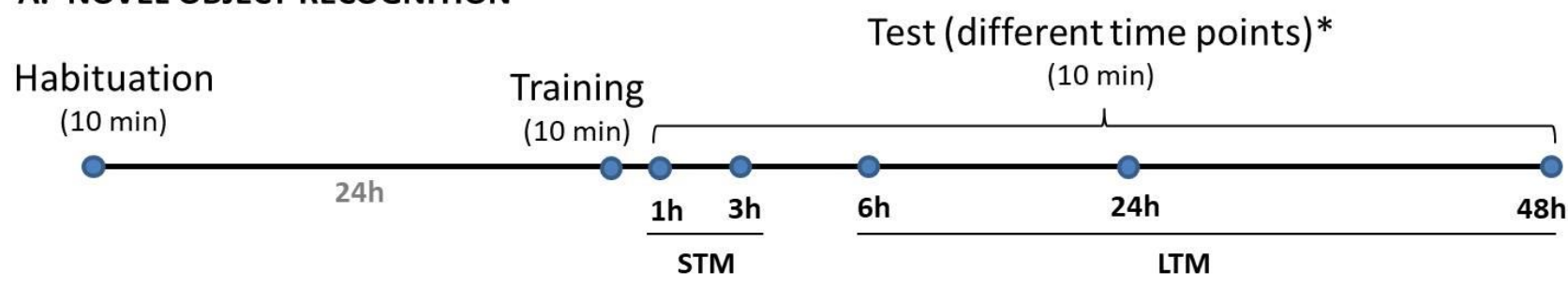

B. NOVEL PLACE RECOGNITION

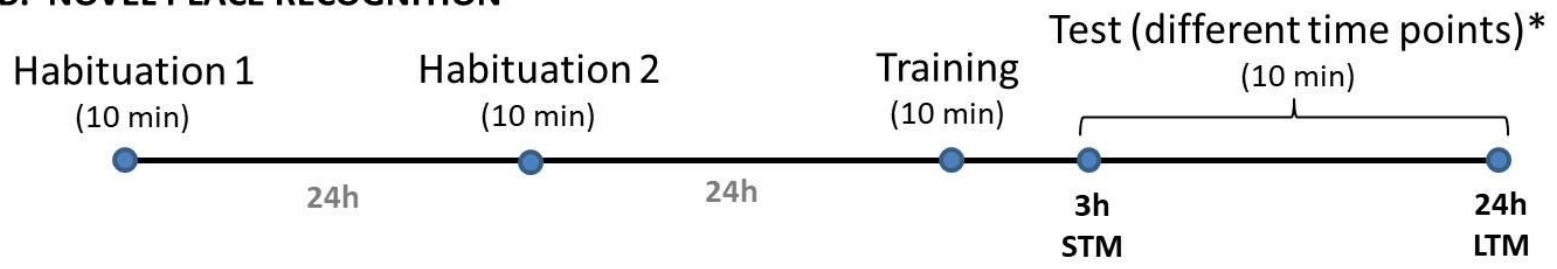

\section{CONTEXT RECOGNITION}

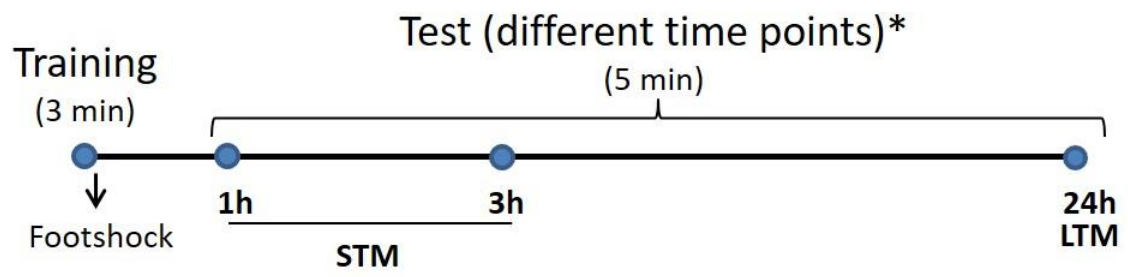

D. TRACE/DELAY FEAR CONDITIONING

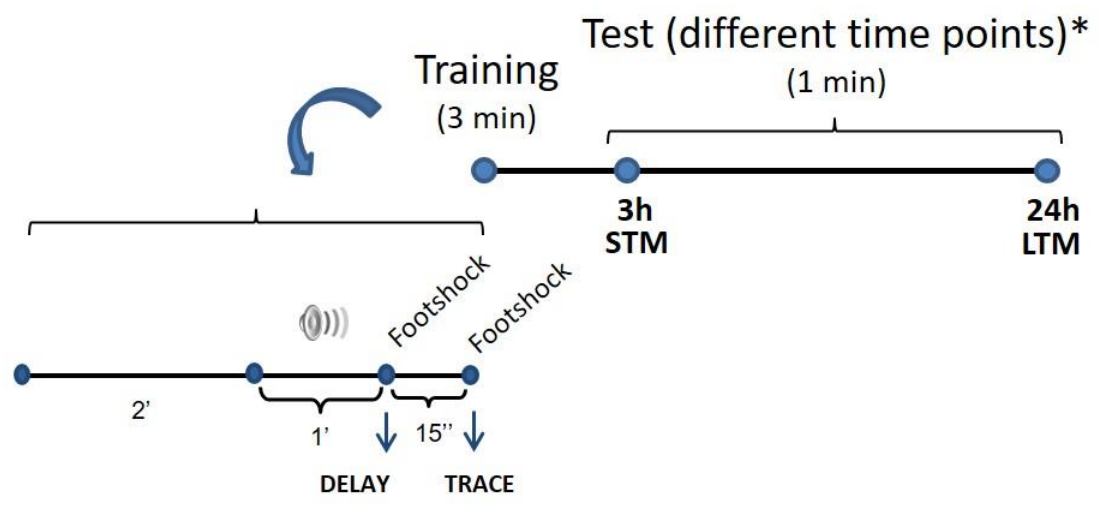

Supplementary Figure 2. Timeline scheme of the behavioral tests performed in the study. Scheme showing the time intervals and time points when the different behavioral tests were performed, including: Novel object recognition test, novel place recognition test, context recognition test and trace/delay fear conditioning. For every test, each time-point was performed in a different cohort of mice.

*Tests done at different time points were performed by different sets of animals 


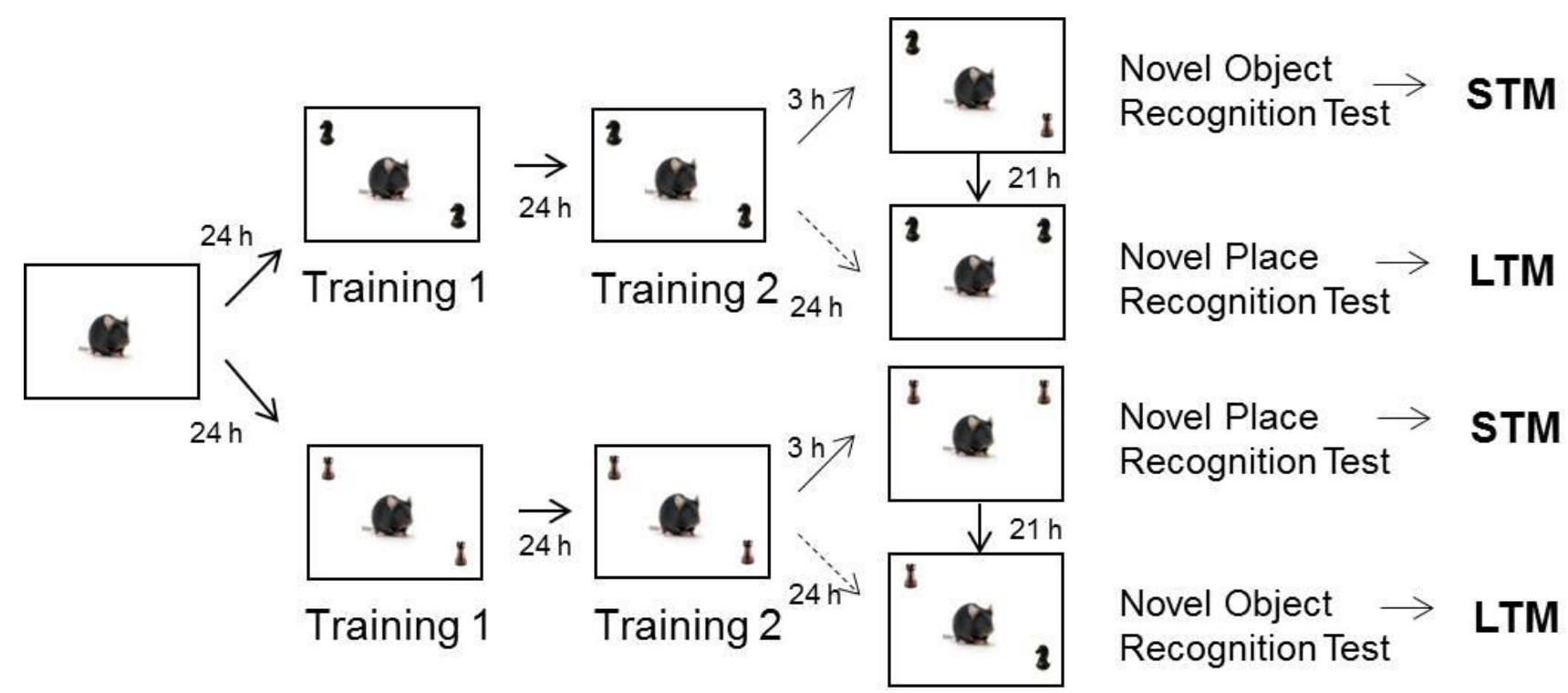

Supplementary Figure 3. Scheme for combined NOR/NPR tasks. Protocol used that combined the novel object-recognition (NOR) test and the novel place-recognition (NPR) test in order to study short-term and long-term memory in the same animal (see Material and methods section for details). 
a

T-maze

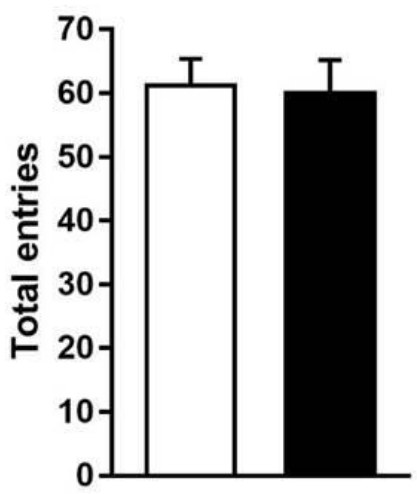

Wild-type b

Y-maze

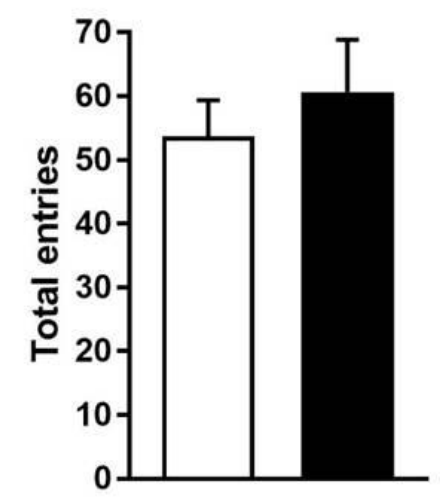

PKC-gamma KO

Supplementary Figure 4. Locomotor activity measurements in spatial memory performance tests. No significant differences in total entries were observed between PKC-gamma KO mice compared with WT neither in the T-maze $[\mathrm{F}(1,25)=0.031, \mathrm{p}=0.861](\mathbf{a})$ or the $\mathrm{Y}$-maze $[\mathrm{F}(1,16)=$ $0.373, \mathrm{p}=0.55]$ (b). Data are expressed as mean \pm s.e.m. 
a

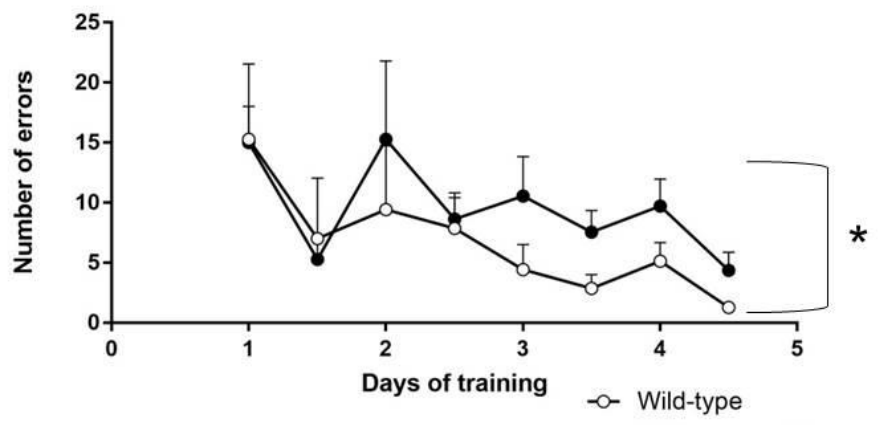

$24 \mathrm{~h}$

b

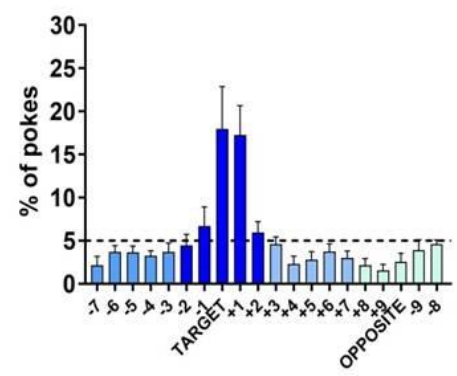

$7 \mathrm{~d}$

d

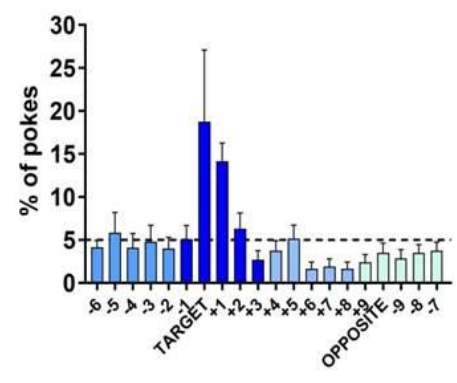

Wild-type

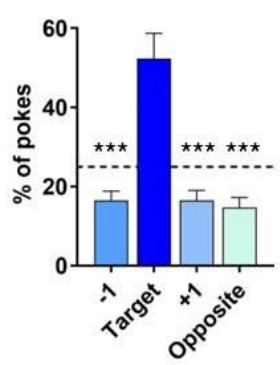

c

PKC-gamma KO
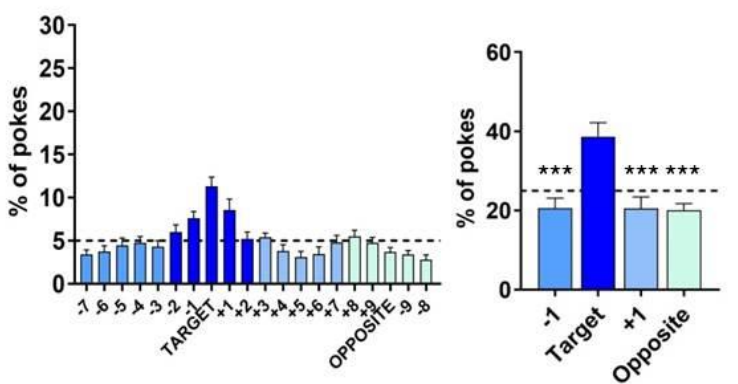

e

PKC-gamma KO
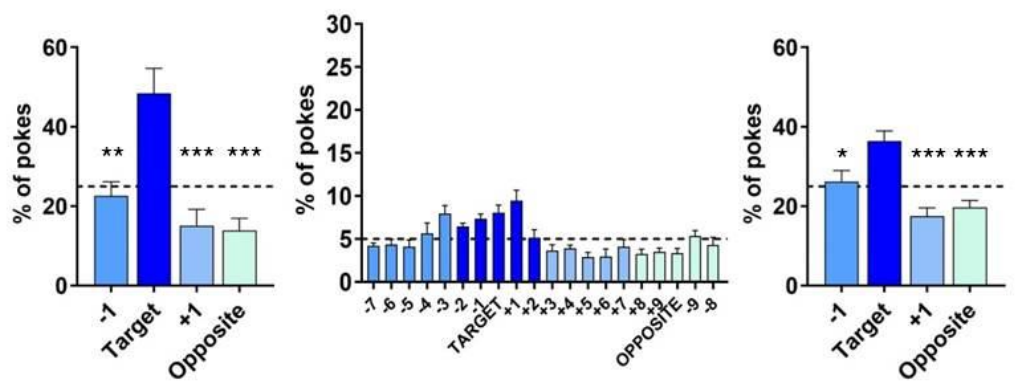

f

Barnes-maze 24

g Barnes-maze $7 \mathrm{~d}$
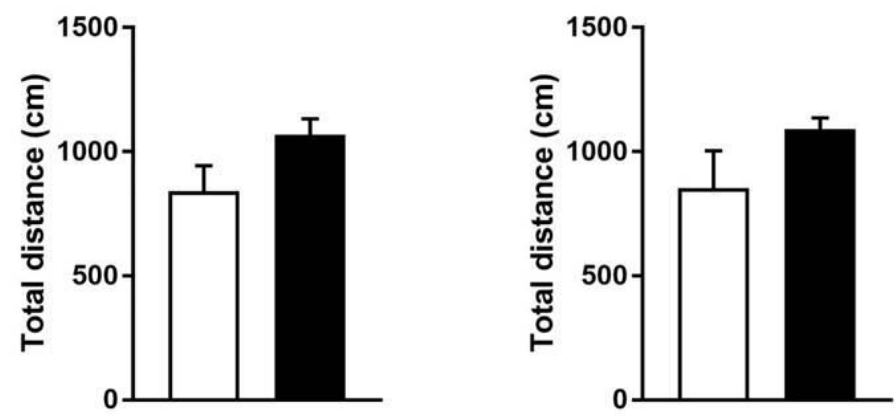

Supplementary Figure 5. Spatial preference memory was evaluated in the PKC-gamma KO mice. Learning and spatial memory were studied using the Barnes Maze task. (a) No differences were observed between the PKC-gamma $\mathrm{KO}$ and wild-type mice during training sessions [genotype: $\mathrm{F}(1,16)=1.897, p=0.187$; time (trial): $\mathrm{F}(7,112)=2.237, p<0.05$; interaction: $\mathrm{F}(7$, $112)=0.315, p=0.946] .24 \mathrm{~h}(\mathbf{b}-\mathbf{c})$ and $7 \mathrm{~d}(\mathbf{d}-\mathbf{e})$ after the last training sessions memory retention was assessed. At the first trial test, the \% of pokes in the target quadrant in WT (b) and PKC- 
gamma KO (c) was higher than in the other quadrants (b: Target vs -1 $[\mathrm{F}(1,12)=27.773, p<0.001]$, Target vs $1[\mathrm{~F}(1,12)=27.148, p<0.001]$, Target vs Opposite $[\mathrm{F}(1,12)=29.919, p<0.001]$; $\mathbf{c}$ : Target vs $-1[\mathrm{~F}(1,20)=17.289, p<0.001]$, Target vs $1[\mathrm{~F}(1,20)$ $=15.686, p<0.001]$, Target vs Opposite $[\mathrm{F}(1,20)=22.740, p<0.001])$. In the second trial test, the $\%$ of pokes were also higher in the target quadrat for WT (d) and PKC-gamma mice (e) (d: Target vs $-1[\mathrm{~F}(1,12)=12.643, p<0.01]$, Target vs $1[\mathrm{~F}(1,12)=19.351, p<0.001]$, Target vs Opposite $[\mathrm{F}(1,12)=24.014, p<0.001]$; e: Target vs $-1[\mathrm{~F}(1,20)=7.322, p<0.05]$, Target vs 1 $[\mathrm{F}(1,20)=32.857, p<0.001]$, Target vs Opposite $[\mathrm{F}(1,20)=29.88, p<0.001])$. (f-g). In Barnes Maze task no significant differences in total distance were observed in the test trial $[24 \mathrm{~h}$ : $\mathrm{F}(1,16)=3.981, \mathrm{p}=0.063 ; 7 \mathrm{~d}: \mathrm{F}(1,16)=3.305, \mathrm{p}=0.087$ ] revealing that differences between groups described in Figure 1 are not due to alterations in exploratory behavior or locomotor activity]. Data are expressed as mean \pm s.e.m. $* \mathrm{p}<0.05, * * \mathrm{p}<0.01 * * * \mathrm{p}<0.001$ (compared to target quadrant). 
a

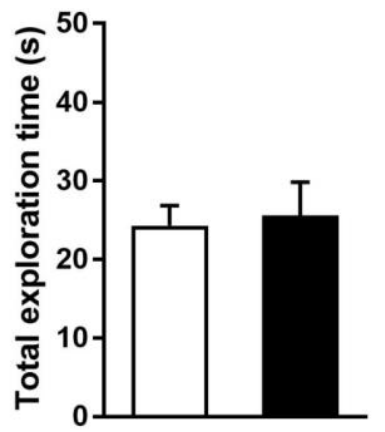

d

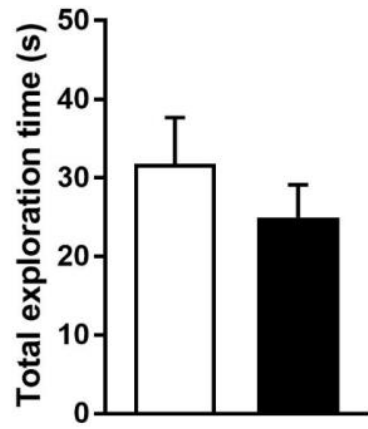

f

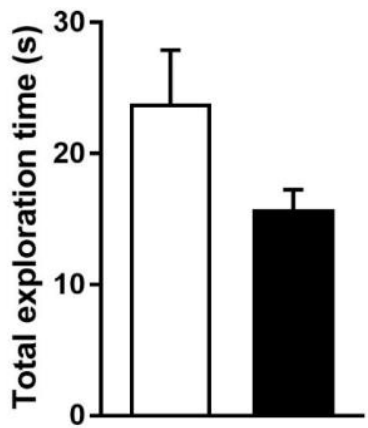

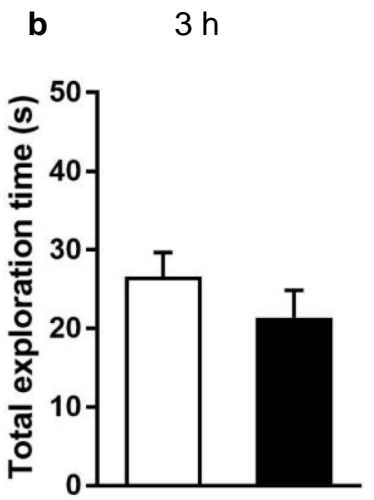

e

$48 \mathrm{~h}$

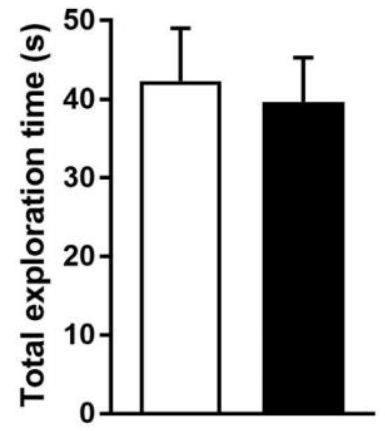

g

$24 \mathrm{~h}$

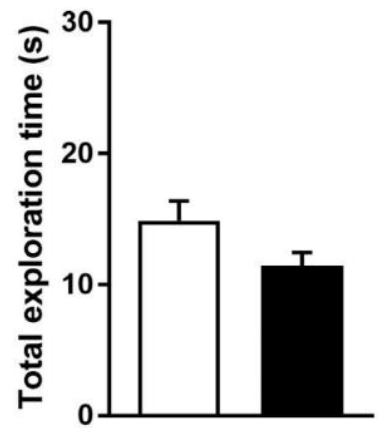

c $\quad 6 \mathrm{~h}$

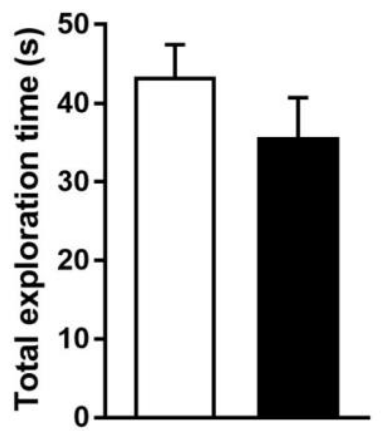

Wild-type

PKC-gamma KO

Supplementary Figure 6. Exploration time on the test session for short-term and long-term novel object-recognition test and novel place-recognition test. No significant differences in total exploration time were observed between PKC-gamma KO mice compared with WT in shortterm $((\mathbf{a}) 10 \mathrm{~min}[\mathrm{~F}(1,17)=0.066, \mathrm{p}=0.80]$ and $(\mathbf{b}) 3 \mathrm{~h}[\mathrm{~F}(1,13)=1.268, \mathrm{p}=0.28])$ and long-term memory $((\mathbf{c}) 6 \mathrm{~h}[\mathrm{~F}(1,13)=1.451, \mathrm{p}=0.25],(\mathbf{d}) 24 \mathrm{~h}[\mathrm{~F}(1,20)=0.903, \mathrm{p}=0.353]$ and (e) $48 \mathrm{~h}$ $[\mathrm{F}(1,16)=0.088, \mathrm{p}=0.77])$ in the novel object-recognition test neither in short-term (f) $3 \mathrm{~h}$ $[F(1,16)=3.467, p=0.081])$ and long-term $(\mathrm{g}) 24 \mathrm{~h}[\mathrm{~F}(1,15)=50.09, \mathrm{p}=0.070])$ in the novel place-recognition test. These data reveals that differences between groups described in Figure 2 are not due to alterations in exploratory behavior or locomotor activity. Data are expressed as mean \pm s.e.m. 
$\square$ Wild-type

PKCgamma KO
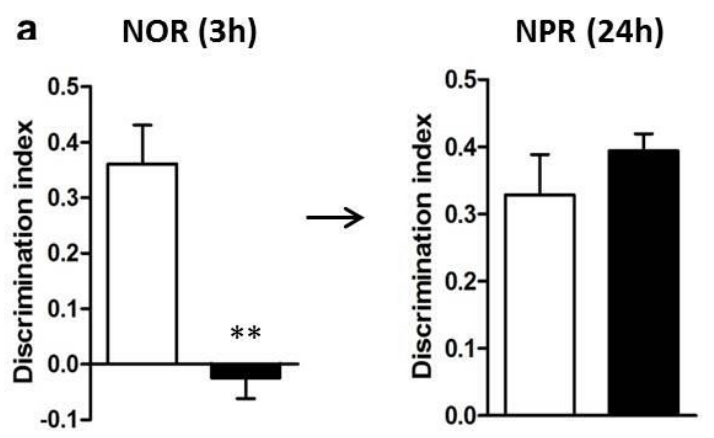

b NPR (3h)

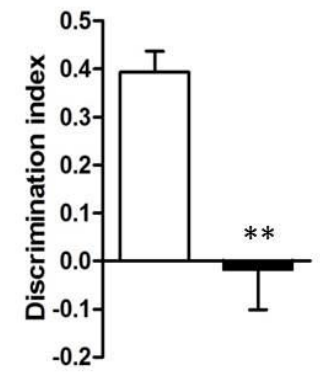

NOR (24h)

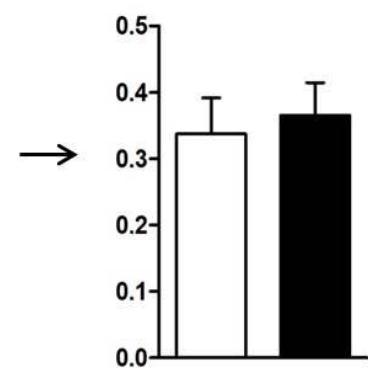

Supplementary Figure 7. Short-term and long-term memories were studied in the same animal by using two different non-emotional memory tasks. (a) One set of animals performed the NOR test to study STM $[\mathrm{F}(1,6)=23.058, p<0.01]$ and the NPR test to study LTM $[\mathrm{F}(1,6)=0.63, p=0.458]$ while another set (b) performed the NPR test to study STM $[\mathrm{F}(1,7)=15.948, p<0.01]$ and the NOR test to study LTM $[\mathrm{F}(1,8)=0.144, p=0.714]$. In both cases, PKC-gamma KO animals only present memory impairments when STM was studied, while LTM was preserved. Data are expressed as mean \pm s.e.m. $* * \mathrm{p}<0.01$ (PKC-gamma KO mice compared to WT). 
DG

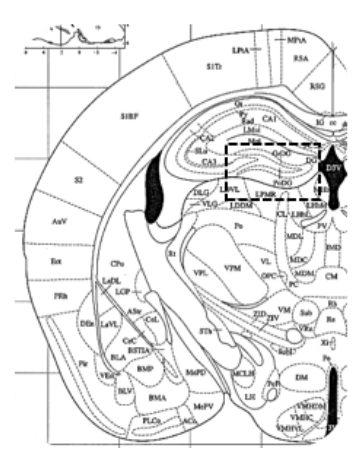

BLA

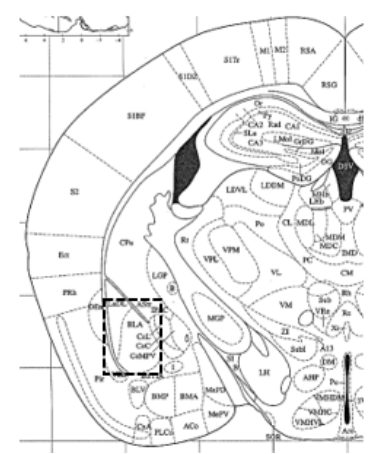

PL

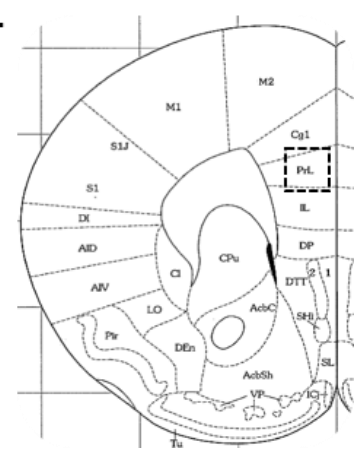

Supplementary Figure 8. Reference atlas pictures indicating the exact region where the cellular analysis was performed. 


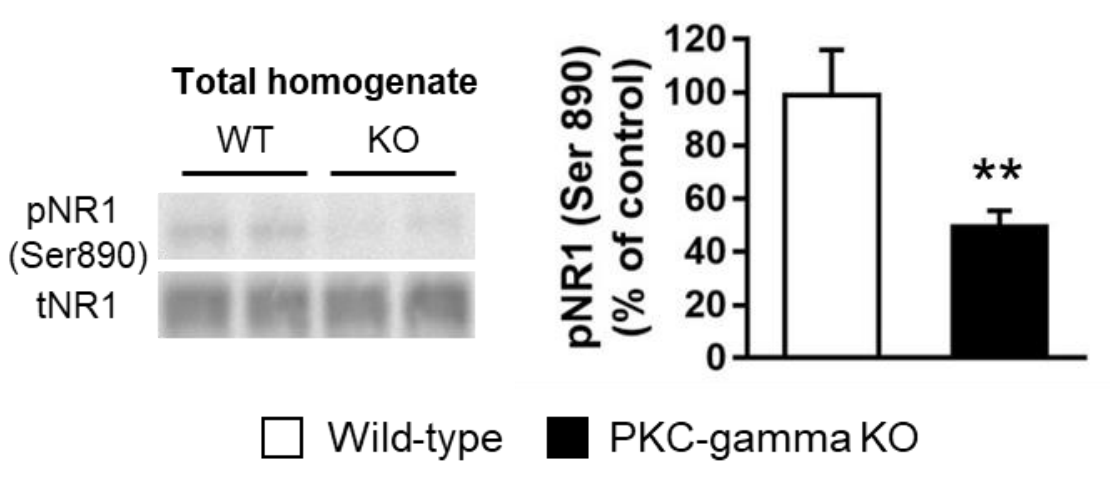

Supplementary Figure 9. PKC-gamma KO mice presented a diminished phosphorylation of serine 890 in NR1 subunit. a significant difference in the phosphorylation level of the NR1 subunit at Ser890 was observed between WT and PKC-gamma KO (n=6-7) $[\mathrm{F}(1,11)=9.846$, $\mathrm{p}<0.01$ ]. Data are expressed as mean \pm s.e.m. $* * \mathrm{p}<0.01$ (PKC-gamma KO compared to WT) 